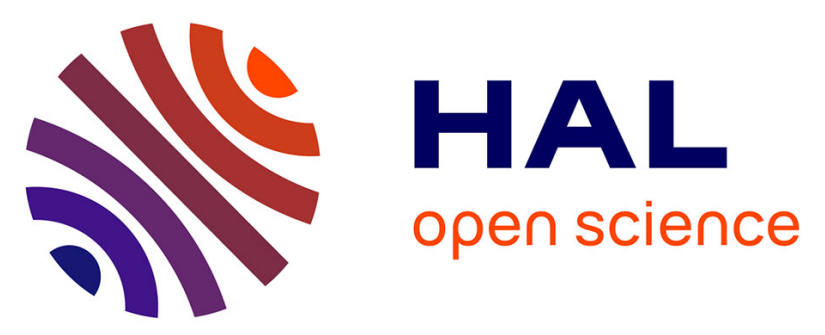

\title{
In Situ Investigation of the THM Behavior of the Callovo-Oxfordian Claystone
}

Nathalie Conil, Manon Vitel, Carlos Plua, Minh-Ngoc Vu, Darius Seyedi, Gilles Armand

\section{- To cite this version:}

Nathalie Conil, Manon Vitel, Carlos Plua, Minh-Ngoc Vu, Darius Seyedi, et al.. In Situ Investigation of the THM Behavior of the Callovo-Oxfordian Claystone. Rock Mechanics and Rock Engineering, 2020, 53 (6), pp.2747-2769. 10.1007/s00603-020-02073-8 . ineris-03318329

HAL Id: ineris-03318329

https://hal-ineris.archives-ouvertes.fr/ineris-03318329

Submitted on 9 Aug 2021

HAL is a multi-disciplinary open access archive for the deposit and dissemination of scientific research documents, whether they are published or not. The documents may come from teaching and research institutions in France or abroad, or from public or private research centers.
L'archive ouverte pluridisciplinaire $\mathbf{H A L}$, est destinée au dépôt et à la diffusion de documents scientifiques de niveau recherche, publiés ou non, émanant des établissements d'enseignement et de recherche français ou étrangers, des laboratoires publics ou privés. 


\title{
In Situ Investigation of the THM Behavior of the Callovo-Oxfordian Claystone \\ Nathalie Conil ${ }^{1,3}$, Manon Vitel ${ }^{2}$, Carlos Plua ${ }^{2}$, Minh Ngoc $\mathrm{Vu}^{2}$, Darius Seyedi ${ }^{2}$, Gilles Armand ${ }^{1}$
}

1 Meuse/Haute Marne Underground Research Laboratory, Andra, Bure, France

2 Andra, Châtenay-Malabry, France

3 Present Address: Ineris, Nancy, France

4 Present Address: CEA Saclay, Gif-sur-Yvette, France

Keywords : Claystone · In situ experiments · Thermo-hydro-mechanical (THM) behavior · Permeability · Thermal pressurization coefficient

\begin{abstract}
The thermo-hydro-mechanical behavior of the host rock is essential while designing an underground radioactive waste disposal repository, and in particular, while considering the long-term safety of the facility. In 2000, the French National Radioactive Waste Management Agency (Andra) started constructing an underground research laboratory located in the Meuse Haute Marne to carry out a research program aiming to demonstrate the feasibility of constructing and operating a radioactive waste disposal facility in the Callovo-Oxfordian claystone, and to optimize its implementation. To study the thermo-hydro-mechanical effects of the early thermal phase on the clay host rock of a deep repository, Andra has performed various in situ heating tests; one of them is called the TED experiment. The aim of the TED experiment was to measure the evolution of the temperature and pore pressure fields around several heaters and to back-analyze the thermo-hydro-mechanical properties of the Callovo-Oxfordian claystone. Thermal conductivity and heat capacity values were determined based on the back-analysis of the in situ measurements and compared to those measured on samples. The in situ experimental data and numerical model confirm the anisotropic behavior of the claystone. The TED experiment results demonstrate the ability of current models to predict the evolution of temperature and pore pressure in the far field of disposal cells.
\end{abstract}

\section{Introduction}

Deep argillaceous formations are considered as potential host rock for radioactive waste repositories in several countries (France, Belgium, Switzerland, etc.). They exhibit favorable characteristics such as very low permeability, a significant retention capacity for radionuclides, and low molecular diffusion rates. In France, the Callovo-Oxfordian claystone (COx) has been selected as a potential host rock for high-level (HLW) and intermediate-level long-lived (IL-LLW) waste.

The heat released from high-level radioactive waste (leading to temperatures up to about $90{ }^{\circ} \mathrm{C}$ ) causes a pore pressure increase within the surrounding rock resulting from the combinated volumetric deformations of the pore water and the solid skeleton. These volumetric deformations are mainly due to the difference between the thermal expansion coefficients of the pore water $\left(\sim 2.3 \times 10^{-4} \mathrm{~K}^{-1}\right.$ at 
$20^{\circ} \mathrm{C}$ and $\sim 7.2 \times 10^{-4} \mathrm{~K}^{-1}$ at $\left.90^{\circ} \mathrm{C}\right)$ and of the solid skeleton $\left(\sim 4 \times 10^{-5} \mathrm{~K}^{-1}\right.$ for the COx $)$ and thermal stresses. The low permeability of the rock and its relative rigidity limit release of the induced pressure build-up. This phenomenon has been observed in undrained laboratory tests conducted on COx (Mohajerani et al. 2012), Boom clay (Monfared et al. 2013), and Opalinus clay (Monfared et al. 2011). For the in situ test and repository design, the geological structure including the boundary condition also affects the pore pressure increase.

Thermo-hydro-mechanical (THM) behavior of the COx is one of the key elements to consider during the design and safety calculation for high-level (HLW) and intermediate-level long-lived (IL-LLW) waste disposal.

Since 2000, the French National Radioactive Waste Management Agency (Andra) has been operating an Underground Research Laboratory (URL) in Bure (Eastern France). In this laboratory, in situ investigations are performed in the COx layer at two depths $(445 \mathrm{~m}$ for the experimental drift, and $490 \mathrm{~m}$ for the main level) to study the feasibility of a deep geological repository in the formation. Andra has defined a specific research program based on laboratory tests, numerical modeling and in situ tests to better assess the THM effects of the thermal transient stage on the COx claystone.

As explained by Armand et al. (2017a, b), this program aims to demonstrate the suitability of the French HLW disposal concept in the COx claystone and to optimize it. A stepwise approach has been adopted, based on demonstration and scientific milestones. Various simple experiments at different scales - at borehole scale with diameters from 100 to $250 \mathrm{~mm}$ (Wileveau and Su 2007) and at full-scale with a $0.7 \mathrm{~m}$ diameter micro-tunnel (Morel et al. 2013) were envisaged. The experiments became more elaborate with time, in order to test different aspects of the concept, to optimize the design and to finally achieve a demonstration experiment.

Similar in situ heating tests have also been performed in other URLs: CACTUS, ATLAS and CERBERUS tests in Boom clay at the HADES URL (Belgium) (Bernier and Neerdael 1996; De Bruyn and Serge 2002), and the HE-D test in Opalinus clay at the Mont Terri URL (Switzerland) (Wileveau and Rothfuchs 2007).

The present paper focuses on the TED experiment and its main objectives to improve understanding of the COx THM behavior and to estimate the main THM parameters for intact COx claystone.

In the second section of this paper, the geological context of the Meuse/Haute-Marne URL is described. The third section presents the objectives of the test along with its characteristics. Finally, the results of the experiment are described and interpreted in the fourth section.

\section{Geological Context}

\subsection{Meuse/Haute-Marne Underground Research Laboratory (MHM URL)}

The Meuse/Haute-Marne URL was set up on the Eastern boundary of the Paris Basin. In the URL area, the COx stratum lies between depths of 420 and $550 \mathrm{~m}$. It is overlain and underlain by poorly permeable carbonate formations.

In the URL, an anisotropic in situ stress state has been observed. The largest principal stress is a horizontal one; the vertical and the minor horizontal stresses are similar to each other (Wileveau et al. 2007). At the $-490 \mathrm{~m}$ main level of the URL, the major horizontal component $\sigma \mathrm{H}$ (oriented $155^{\circ} \pm 10^{\circ}$ ) is about $16 \mathrm{MPa}$, and the vertical component $\sigma \mathrm{V}$ and the minor horizontal component oh (oriented $065^{\circ} \pm 10^{\circ}$ ) are about $12 \mathrm{MPa}$. 
The URL consists of two vertical shafts and a large number of drifts and boreholes set up at depths between 445 and $490 \mathrm{~m}$ (Fig. 1 ). The TED experiment is located at the main 490-m level in the wall of the GED drift.

Fig. 1

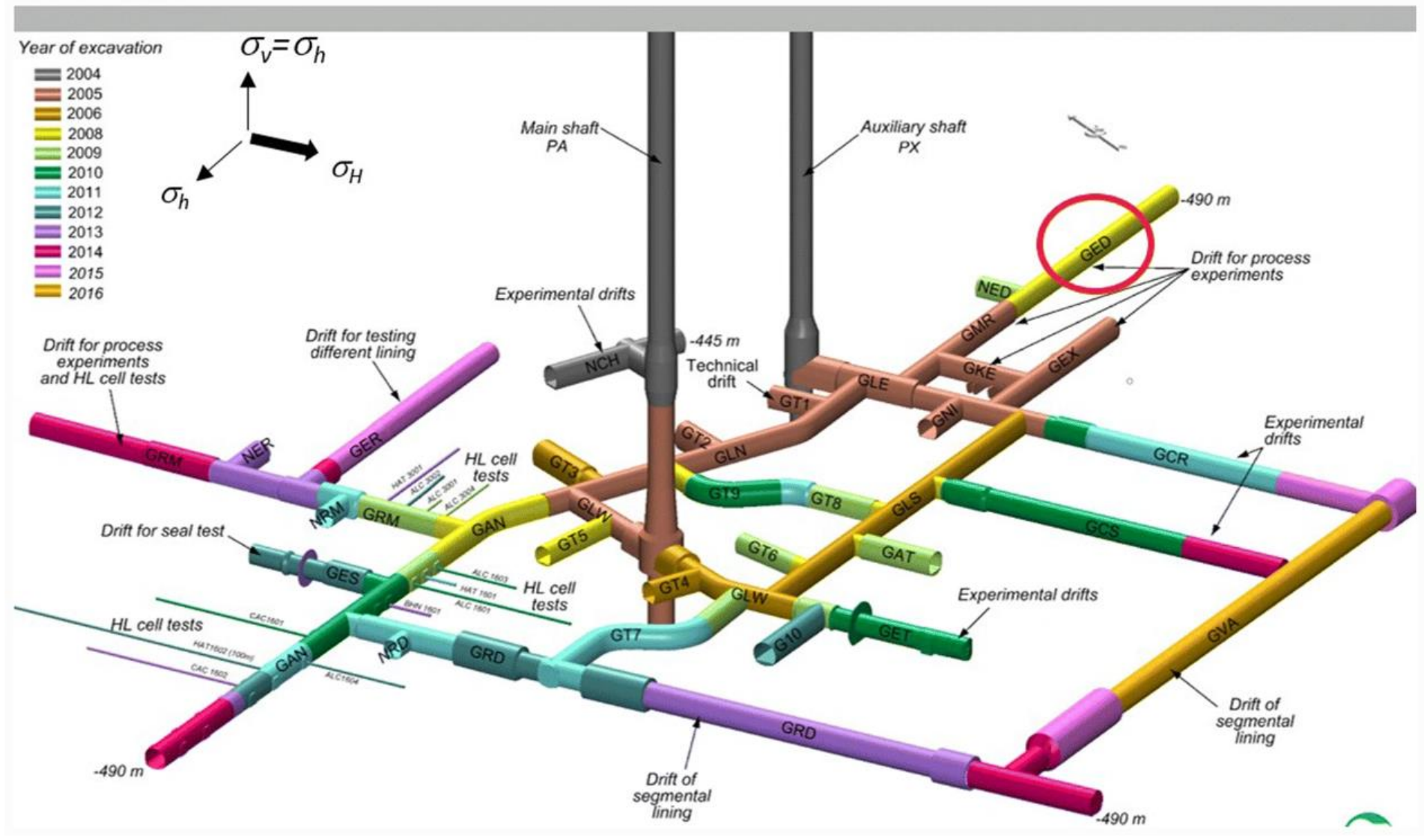

Meuse/Haute-Marne URL plan and principal stress directions

\subsection{Callovo-Oxfordian Claystone}

The Callovo-Oxfordian sedimentary layer is characterized by a dominant clay fraction rich in carbonates, quartz, minor feldspars and accessory minerals. On average, the COx claystone contains $25-55 \%$ clay minerals, $20-38 \%$ carbonates, $20-30 \%$ quartz, $1 \%$ feldspar and small amounts of other inclusions (Andra 2005). The COx layer can be vertically divided into three lithostratigraphic units listed from the base: the clay unit (UA), approximately two-thirds of total layer thickness with the highest clay mineral content (over $40 \%$ on average); the transition unit (UT) and the silty carbonate-rich unit (USC) with the highest carbonate content (40-90\%) and a thickness of 20-30 m. At the main level of the URL, Callovo-Oxfordian claystone represents a clay matrix (clay content ranging from 40 to $60 \%$ ) with carbonate and tectosilicate grain inclusions, i.e. non-porous inclusions considered as rigid compared to the clay matrix. As a result, most of the porosity is located within the clay matrix, and there is a strong correlation between clay content and porosity values at the scale of the CallovoOxfordian layer. The mechanical behavior of the COx primarily depends on its mineralogical composition. Therefore, the behavior observed in the clay-rich unit (UA) is distinct from the behavior of the silty carbonate unit (USC). 
Mineral distribution maps (Robinet et al. 2012) show a preferential orientation of carbonate and tectosilicate inclusions parallel to the bedding plane. Nevertheless, the orientation of clay particles and aggregates with respect to the bedding plane is not as marked as in the case of other indurated clays such as Opalinus clay in Switzerland. This feature leads to a slight anisotropy of most rock properties, particularly with regard to solute diffusion, water permeability, thermal diffusivity and mechanical parameters.

Various laboratory tests were carried out to obtain the physical properties of the COx. The very small mean pore diameter (about $0.02 \mu \mathrm{m}$ ) of the claystone leads to a very low permeability (ranging between $1 \times 10^{-21}$ and $2 \times 10^{-20} \mathrm{~m}^{2}$ ) despite a relatively high porosity (ranging between 14 and $21 \%$, $17.5 \% \pm 1.2 \%$ at the main level of the URL). The claystone is fully saturated and natural water content is around $7 \% \pm 1.7 \%$. For water permeability, a slight anisotropy ratio of about 3 is observed. Note that with regard to the extremely low permeability of the $\mathrm{COx}$, the observed anisotropy ratio remains within the variability of the measured values.

From a thermal standpoint, the specific heat capacity, which depends only on the composition of the rock, is known with a small uncertainty. The specific heat capacity of the solid phase is equal to 800$820 \mathrm{~J} \mathrm{~kg}^{-1} \mathrm{~K}^{-1}$, resulting in a specific heat capacity for the whole saturated material of about $1000 \mathrm{~J} \mathrm{~kg}^{-1} \mathrm{~K}^{-1}$. The thermal conductivity has been determined from various laboratory tests on samples (Armand et al. 2017a, b); the values generally retained for the COx are about 1.9 parallel to the bedding plan and 1.3 perpendicularly.

A detailed summary of the hydro-mechanical behavior of the COx can be found in Armand et al. (2017a, b). As regards the mechanical behavior of the $\mathrm{COx}$, under triaxial compression, it changes from quasibrittle to ductile in response to the confinement stress. The study of the short-term behavior of claystone samples led to the following conclusions: (a) a short linear elastic behavior under very low deviatoric stresses, (b) the onset of plastic strains for relatively low deviatoric stresses, (c) under low confining stresses, a quasi-brittle failure followed by a sharp decrease of the stress level. With increasing confining stress, the failure type changes toward a ductile-like failure with a softening postpeak behavior. Under triaxial conditions, the transition confining stress corresponding to a completely ductile failure is estimated to be about $20 \mathrm{MPa}$. The post-peak behavior yields to a residual one, where the rock behaves as a cohesionless completely frictional material corresponding to the behavior of the created macro-cracks. The claystone exhibits a brittle behavior under tensile loading. Tensile strength of the COx depends on its mineralogy and increases with the carbonate ratio.

Mechanical tests performed on samples obtained following different orientations show a crossisotropic behavior. The parallel-to-bedding stiffness of the COx is greater than its perpendicular-tobedding stiffness (anisotropy ratio ranging between 1.2 and 2.0).

\section{Concept of the Experiment}

\subsection{Context}

The current French concept for the HLW repository consists in its placement in a set of parallel microtunnels of 0.7-1.0 m diameter and 80-150 m length drilled from the access tunnels (Vu et al. 2015). The temperature rise of the waste will lead to a significant change in the stress field around the microtunnels.

Indeed, the large number of similar cells implies lateral symmetry conditions. Similar temperature rises, from two neighboring cells, prevent any hydraulic or thermal exchange between two halfdistances between cells. Lateral expansion is also prevented due to this lateral symmetry condition. Conversely, thermal load provokes a vertical expansion of the rock mass. Thermo-mechanical 
compressive stresses are thus induced while the total vertical stress remains almost constant. The lowpermeability COx claystone behaves as an undrained porous medium at the beginning of heating (Seyedi et al. 2017). Thus, for undrained conditions, the total stress change contributes to the pore pressure build-up in accordance with Eq. (1) assuming elastic behavior of the material (Ghabezloo and Sulem 2009; Vu et al. 2019).

$\Delta p=B \Delta m+\Delta T$

where $\sigma \mathrm{m}$ is the total mean stress, $\mathrm{p}$ the pore pressure, T the temperature. B is Skempton's coefficient, which is

$$
B=\frac{\frac{1}{K}-\frac{1}{K_{\mathrm{s}}}}{\phi_{0}\left(\frac{1}{K_{\mathrm{f}}}-\frac{1}{K_{\mathrm{s}}}\right)+\frac{1}{K}-\frac{1}{K_{\mathrm{s}}}}
$$

and $\Lambda$ is the thermal pressurization coefficient

$$
\Lambda=\frac{\phi_{0}\left(\alpha_{\mathrm{f}}-\alpha\right)}{\phi_{0}\left(\frac{1}{K_{\mathrm{f}}}-\frac{1}{K_{\mathrm{s}}}\right)+\frac{1}{K}-\frac{1}{K_{\mathrm{s}}}},
$$

where $\alpha \mathrm{f}$ is a function of temperature, $\mathrm{K}$ the drained bulk modulus, $\mathrm{Ks}$ the unjacketed modulus, $\mathrm{K} f$ the fluid compression modulus, and af and $\alpha$ are, respectively, the volumetric thermal expansion coefficient of pore fluid and solid phase.

Thus, the thermal pressurization coefficient alone cannot be used to estimate the pressure build-up without considering the effects of the total stress changes at the beginning of the in situ heating test.

The TED experiment aims to reproduce at small scale a similar geometry to the HLW zone in order to study the THM effect of superposition of temperature fields on THM behavior of the rock mass (i.e. with various heat sources)

While the geometry of the experiment mimics the geometry of the HWL zone, the small scale implies different boundary conditions and therefore different changes in stress.

\subsection{Experimental Set-up Design}

The principle of the TED experiment was to study the evolution of temperature, pore pressure and deformation around three heaters located parallel to each other in the COx.

The TED experiment continued the research conducted in the TER experiment (Wileveau and Su 2007) with some enhancements. In particular, special attention was paid to the uncertainties regarding the sensors' location, limitation of temperature and the stress field influence of nearby drifts. The main difference between the TER and TED experiments is the number of heaters: one heater in the first test and three in the second. The boreholes were drilled parallel to the maximal horizontal stress and placed about $2.7 \mathrm{~m}$ away from each other, in a ratio consistent with the repository concept. This configuration includes planes of symmetry with no-flux boundary conditions between two heaters. This geometry meant that thermal overpressures and their evolution in this no-flux plane could be checked experimentally. 


\subsection{Characteristics of the Experiment}

The TED experiment was heavily instrumented to follow the temperature change within the whole influenced domain.

\subsubsection{Layout of the Experiment and Instrumentation}

The overall layout of the experiment can be seen in Fig. 2. It included 3 heating boreholes (TED1201TED1203) and 23 instrumented observation boreholes:

Fig. 2

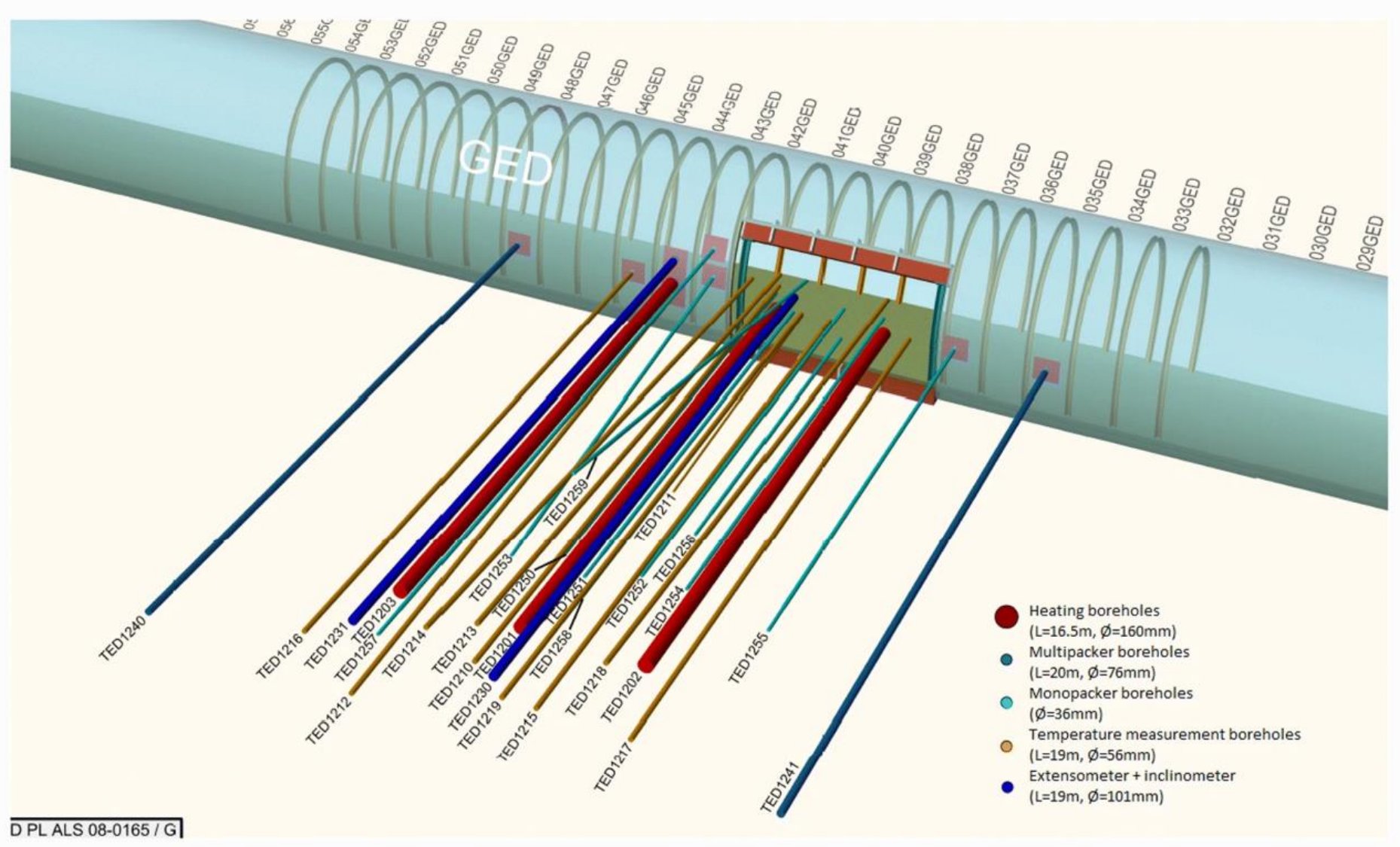

Three-dimensional layout of the TED experiment indicating heaters and instrumentation boreholes

- 12 boreholes for measuring water pressure (10 monopacker boreholes TED1250-TED1259, 2 multipacker boreholes TED1240 and TED1241). The temperature was measured in each piezometric chamber. These boreholes were backfilled with resin to ensure sealing and low compressibility.

- 9 boreholes for temperature measurement (TED1210, TED1212-TED1219) representing 90 temperature sensors. The boreholes were backfilled with a cement-bentonite grout formulated to reproduce the low permeability of the COx. The temperature sensors in the rock mass recorded the temperature within the heated zone as well as in the non-heated zone. Two kinds of sensors were chosen: duplex PT1000 3-wire sensors and simple PT1000 4-wire sensors. The 'duplex' sensors were redundant sensors placed for confidence in assessing the sensor data on the 14-m plane.

- 2 boreholes for displacement measurement $(2$ extensometers and inclinometers in 2 boreholes TED1230 and TED1231). The deformations induced by the heating are difficult to 
measure in situ because of their low values and to the influence of the heating on the tool. This is why the choice was made to make manual inclinometer and micrometer measurements.

The three horizontal heaters were $4 \mathrm{~m}$ long and installed at the end of $160 \mathrm{~mm}$ diameter and $16 \mathrm{~m}$ long boreholes to avoid the influence of seasonal temperature variations in the GED drift (due to air inlets from the access shaft) and, more generally, to avoid the THM influence of this drift (relative humidity variation, convergence of the wall, etc.). The three boreholes were fully lined. The void between the casing and the claystone was grouted with a standard grouting, as for the deformation measurement boreholes (TED1230 and TED1231). 69 temperature sensors were installed in the 3 heater boreholes (TED1201-TED 1203) with 51 dedicated to temperature measurement on the external casing of the boreholes and 18 located in the heaters to monitor and regulate them. Of the casing sensors, 36 duplex PT1000 3-wire sensors (12 per borehole, 4 sensors diametrically opposed every meter, Fig. 3) were placed on the external casing in the heated zone, while 15 simple PT1000 4wire sensors ( 5 per borehole) were located in the non-heated zone (Fig. 3). To monitor the temperature inside the heaters, 18 sensors were installed, 6 per borehole ( 2 sensors every meter). Two of them were defective from the start in TED1201.

Fig. 3
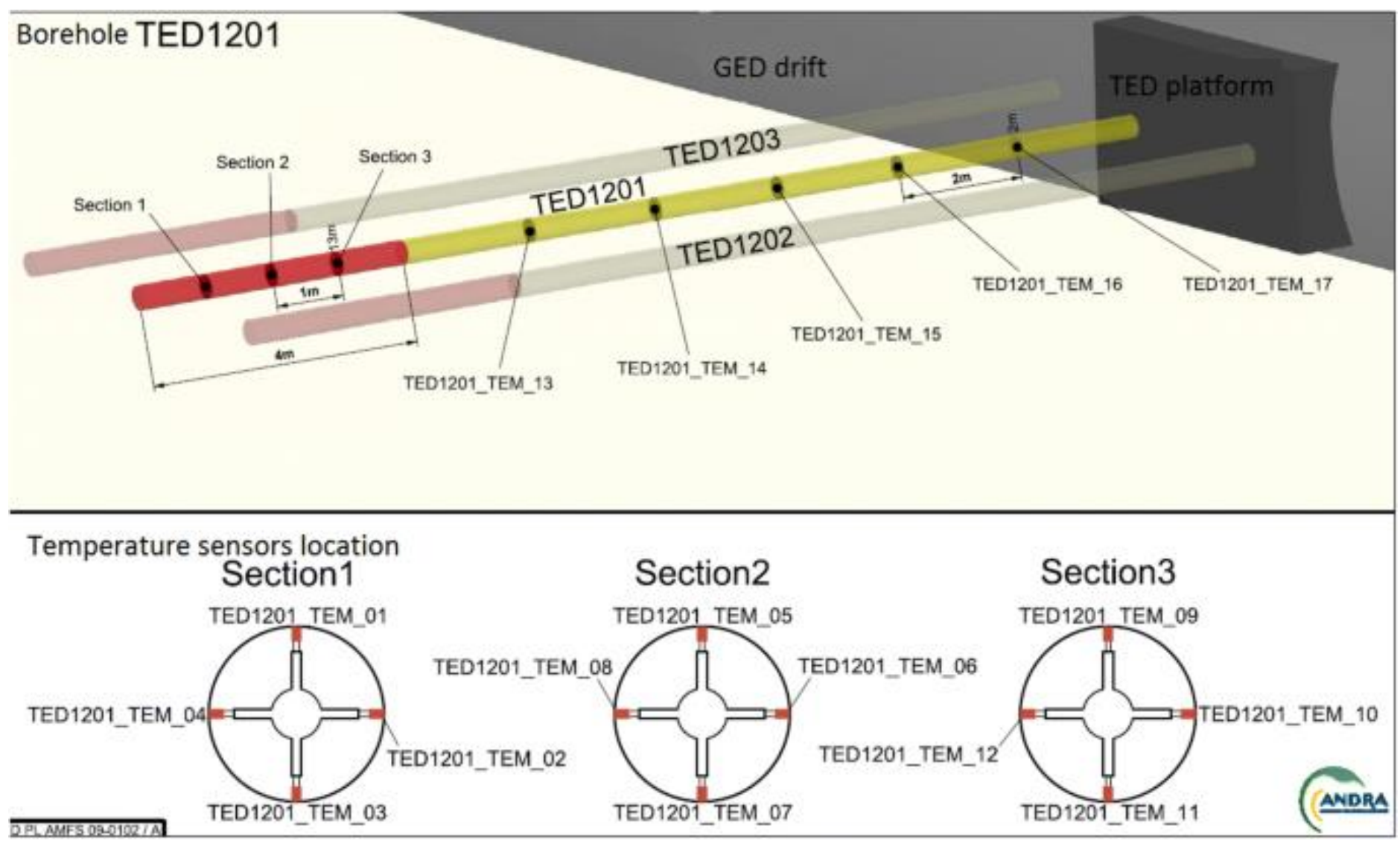

Location of the temperature sensors along the heater boreholes

To optimize inverse problem analysis, efforts were made to reduce the uncertainties regarding sensor location in the boreholes. Possible sensor location errors proved to be an issue for analysis and 
parameter determination in the TER experiment (Garitte et al. 2014). All sensor coordinates were measured.

As the COx claystone exhibits stiffness and strength anisotropy (cross-anisotropic behavior as many sedimentary rocks), the boreholes were positioned both vertically and horizontally around the heaters to measure parameters in both orientations with respect to the bedding.

To effectively control the boundary conditions for modeling purposes, seasonal temperature variations near the GED drift were carefully measured, both within the GED drift and at $30 \mathrm{~cm}$ depth in the ground: 2 PT1000 3-wire temperature sensors for the air temperature in the drift and 8 PT1000 4-wire sensors at $30 \mathrm{~cm}$ depth (TED1270-TED1277).

The monopacker boreholes were close to the heaters in such a way that they could be used to observe the impact of heating on the pore pressure. The multipacker boreholes were further from the heated zone. Boreholes TED1240 and TED1241 were located about $7 \mathrm{~m}$ and $6.5 \mathrm{~m}$ from heater TED1201, respectively, and included 5 and 3 piezometers, respectively. They were designed to record the pressure gradient from the GED drift wall.

The sensor in borehole TED1257 stopped working at the start of heating stage H2.1 (Fig. 5).

The temperature and pore pressure peripheral boreholes were installed in such a way that a large number of sensors lay at $14 \mathrm{~m}$ from the GED drift wall, the plane coinciding with the mid-section of the heaters (Fig. 4).

Fig. 4

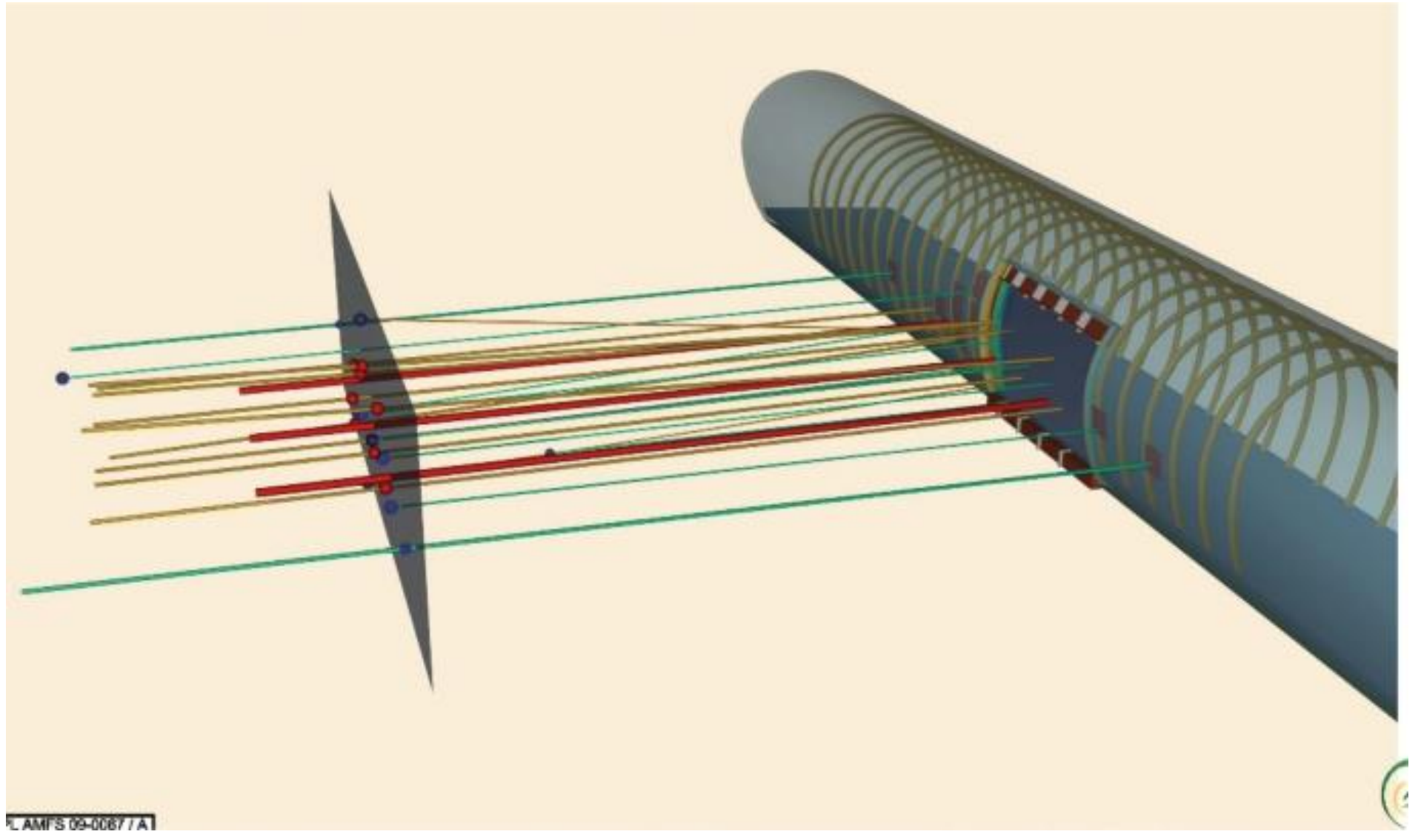

Three-dimensional layout of the TED experiment indicating the 14-m plane that coincides with the mid-section of the heaters 
Manual deformation measurement (axial deformation and inclination in between two anchors at different depth) were performed in the two boreholes TED1230 and TED1231 and appeared to be not reliable. The measurements were stopped in 2012 and they are not presented in this paper.

\subsubsection{Applied Heat}

The power sequences applied in each heater were designed to facilitate interpretation of TED experiment. In particular, during the different steps, the input power was maintained long enough to achieve a quasi-steady thermal state. This precaution was meant to separate the steady-state and transient regimes, and thus to facilitate the distinction between parameters that varied over time (specific heat capacity) and permanent ones (thermal conductivity). Moreover, several steps at distinct power levels $(25 \%, 50 \%$ and $100 \%)$ were used to enable studying the effect of several ranges of temperature increase on the rock mass behavior.

The nominal power for each heater was calculated to achieve a maximum temperature of $90^{\circ} \mathrm{C}$ on the rock-heater interface when the three heaters were switched on. The highest temperature of $90^{\circ} \mathrm{C}$ corresponds to a requirement taken into account in the French repository concept. The history of applied power in the TED experiment can be divided into three main stages, namely two heating stages and one cooling stage (Fig. 5).

Fig. 5

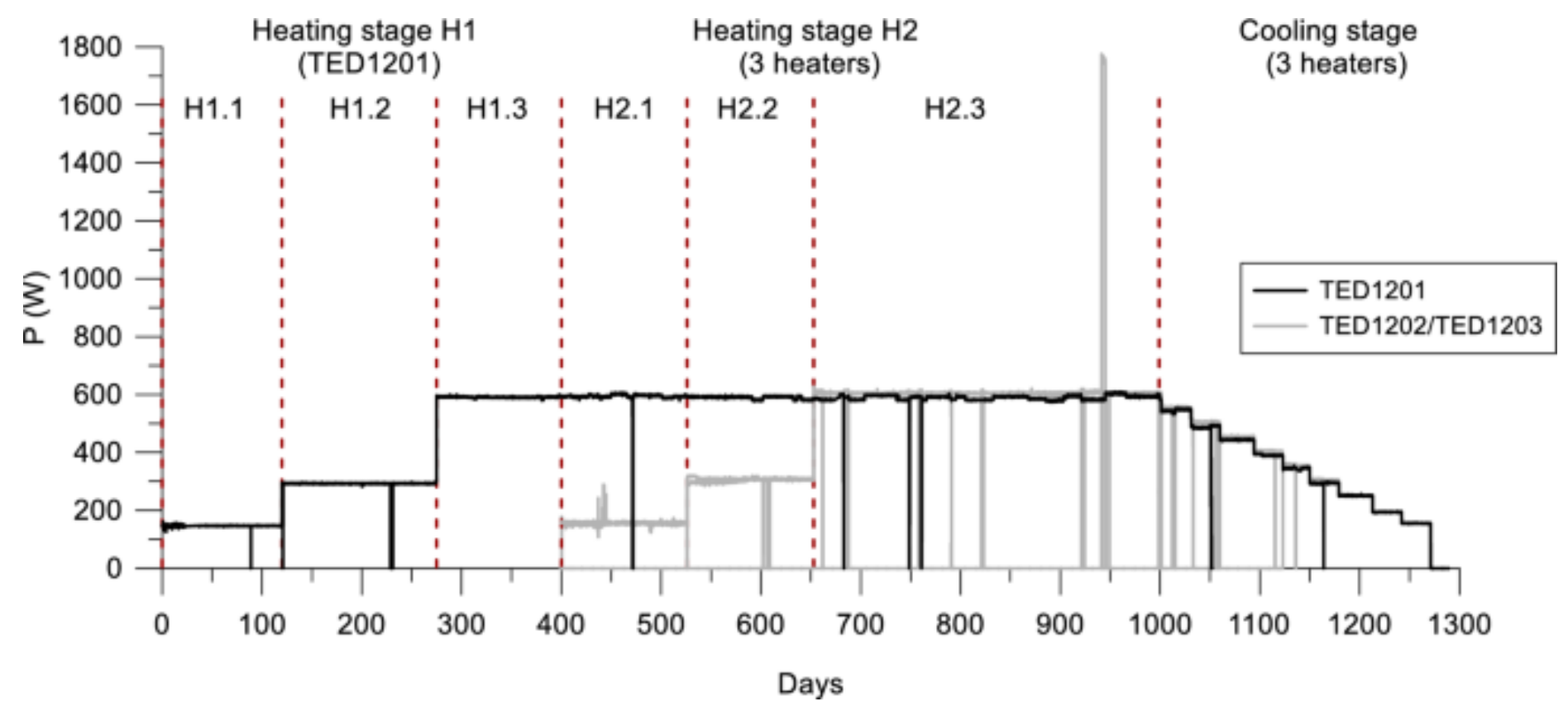

Power history applied to the three heaters during the different stages

The first heating stage started on 25 January 2010 (day 0) when only the central heater TED1201 was turned on. This first stage included three steps (starting at days 0, 120 and 275, respectively) of approximately 4 months:

- H1.1: a power of $150 \mathrm{~W}$ (25\% of nominal power)

- H1.2: a power of $300 \mathrm{~W}$ (50\% of nominal power)

- H1.3: the nominal power of $600 \mathrm{~W}$ 
At day 400 , the second heating stage started with the three heaters turned on, to investigate effects of the additional thermal loads. It lasted 20 months. While the central borehole TED1201 was maintained at nominal power during the whole stage, the same heating load was applied to the two additional boreholes TED1202 and TED1203, following the steps of TED1201 in the first stage:

- H2.1 (starting at day 400): a power of $150 \mathrm{~W}$ applied to TED1202 and TED1203

- H2.2 (starting at day 526): a power of $300 \mathrm{~W}$ applied to TED1202 and TED1203

- H2.3 (starting at day 653): the nominal power of $600 \mathrm{~W}$ applied to TED1202 and TED1203, the three heaters were then maintained at their nominal power for 1 additional year.

On day 999, the cooling stage started. After the power was shut down, the experiment is not considered to be finished. The impact of the decrease of temperatures down to the initial ones, associated with a pressure recovery, was followed to better understand the THM behavior of the COx.

Some significant outages (i.e. more than $1 \mathrm{~h}$ long) occurred during the experiment. These outages can be seen in Fig. 5 but most of them lasted only a few hours and did not impact the pressure and temperature measurements in the rock mass. However, a 48-h-long outage took place at day 229 and led to large pressure and temperature drops in the closest boreholes. Therefore, step H1.2 was extended 1 additional month to allow the pore pressure to rise again and stabilize. The biggest incident occurred from day 941 to day 945 , when the power applied by heater TED1202 increased to more than $1700 \mathrm{~W}$ for 3.5 days.

\subsubsection{Permeability Tests}

Hydraulic tests conducted 6 months after the end of the TER experiment revealed a significant increase in permeability, particularly in the bedding plane. The lack of intermediate hydraulic tests during the experiment meant that the cause of this possible damage could not be determined. It is likely that the complex thermal loading cycle, in particular at the end of the experiment (with alternating episodes of heating and cooling over short intervals), amplified this damage.

Therefore, based on the experience gained on the TER experiment, permeability tests were periodically performed for the TED experiment in all the piezometric chambers to investigate the impact of heat on rock permeability. Several pulse-test campaigns were conducted:

- after installation of the heaters and just before each heating step,

- at the end of each step, once the temperature was stable,

- just before the cooling stage,

- one intermediate campaign during the cooling stage,

- after final heater shutdown, once the pressures were stable,

- once a year during the cooling phase.

\section{Results of the Experiment and Interpretation}

\subsection{Analysis of the Thermal Response}

\subsubsection{Temperature Variations in the Rock Mass}

The location of the temperature sensors in the rock mass is shown in Fig. 6 . All of them can be seen in the plan view and 20 of them are included in the $14-\mathrm{m}$ plane (see cross-section view). The temperature evolution during the heating and cooling phases in this $14 \mathrm{~m}$ plane is shown in Fig. $7 \mathrm{a}, \mathrm{b}$ for boreholes TED1210-TED1219 and TED1250-TED1259. The dotted lines represent the heat power steps. It can be seen that each power step leads to a temperature increase in the peripheral boreholes. The magnitude of this increase and the time at which the increase is detected varied from one point to another. They 
depended on the distance between the sensor and the heater. The sensors located close to heater TED1201 (less than $63 \mathrm{~cm}$ ) were the ones that recorded the highest temperatures: TED1210, TED1219, TED1250 and TED1259. From heat step H2.3, the sensors located close to heater TED1202 (less than $39 \mathrm{~cm}$ ) also recorded high temperatures: TED1217 and TED1254. The highest temperature was recorded by TED1250 and TED1217 (located at about $30 \mathrm{~cm}$ of heaters TED1201 and TED1202, respectively) and was $66^{\circ} \mathrm{C}$ if the incident of August 2012 (day 941) is not taken into account. 
Fig. 6

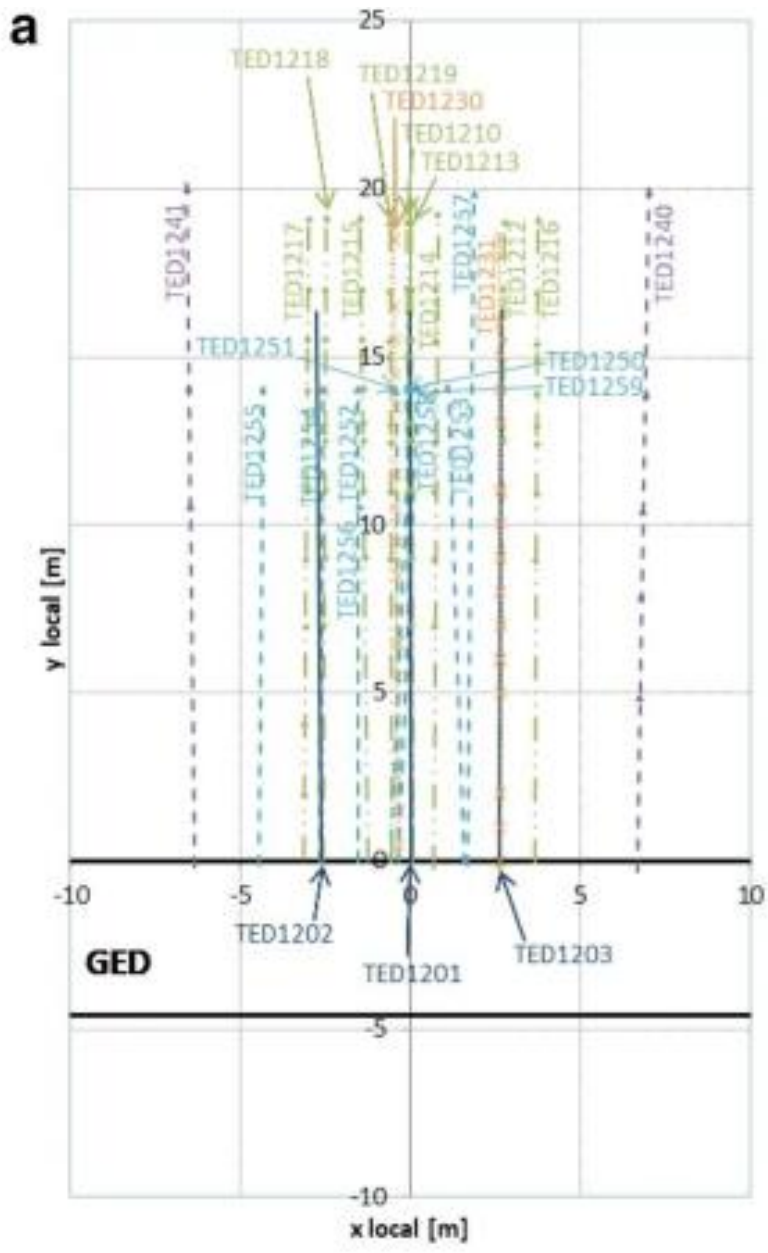

b

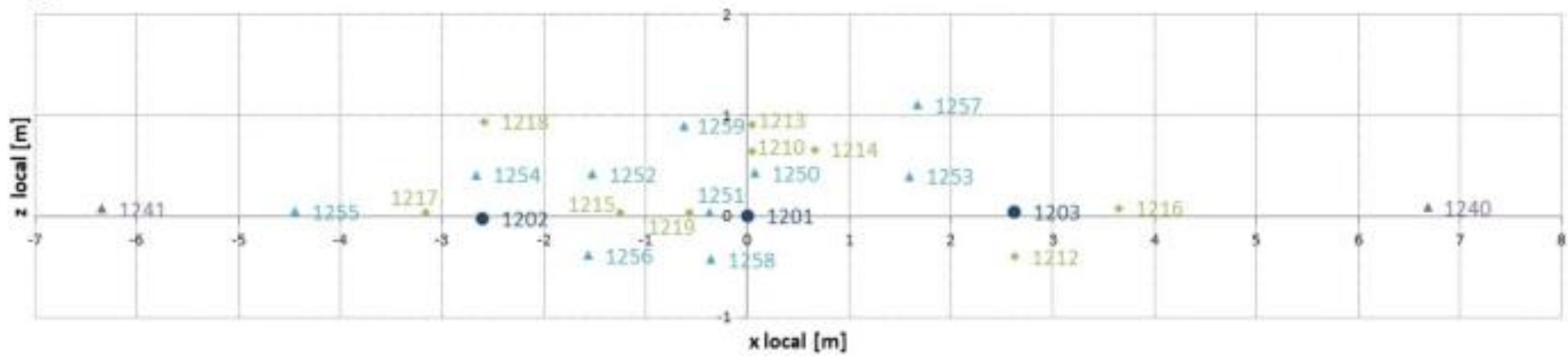

a Plan view of the temperature (green diamonds), pressure (cyan triangles for monopackers and purple triangles for multipackers) and displacement (orange crosses) measurement boreholes and sensors in the rock mass and $\mathbf{b}$ cross-section view at the $14-\mathrm{m}$ plane of the temperature and pressure sensors 
Fig. 7
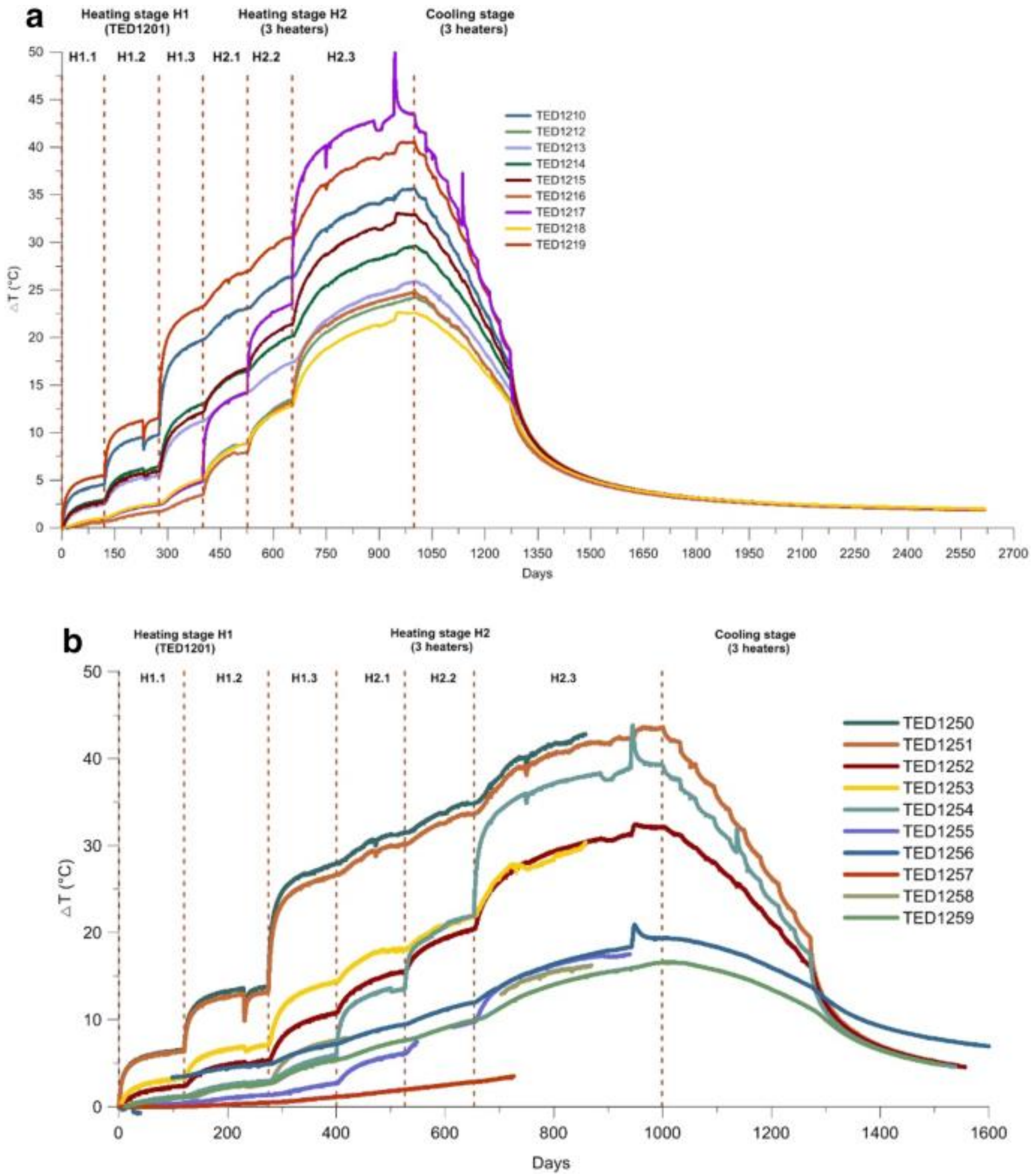

Temperature history at the 14-m plane recorded by sensors located in peripheral boreholes a TED1210-TED1219 and b TED1250-TED1259 (sensors in TED1256 and TED1257 are located at $10.5 \mathrm{~m}$ and $20 \mathrm{~m}$ deep, respectively) 
The cooling phase started on day 999. The effect of the 30-day-long decreasing power steps can be directly seen on the temperature evolution for all the sensors. On the final shutdown at day 1271 , the recorded temperatures lie between $33^{\circ} \mathrm{C}$ and $41^{\circ} \mathrm{C}$, i.e. far from the initial temperature $\left(22^{\circ} \mathrm{C}\right)$. It should be noted that around day 2600 , the temperatures had almost stabilized and were about $24^{\circ} \mathrm{C}$ for all the sensors.

Moreover, the temperature measurements provide clear evidence of thermal anisotropy. To highlight this behavior, Fig. 8 shows the temperature evolution in boreholes TED1210 and TED1219 at $14 \mathrm{~m}$ from the drift. The sensors of the two boreholes are approximately at equal distance from the heater (TED1210 at $61 \mathrm{~cm}$ and TED1219 at $57 \mathrm{~cm}$ from heater TED1201 in the $14 \mathrm{~m}$ plane) but one borehole is in the bedding plane (TED1219) while the other is in the perpendicular direction (TED1210). It can be seen in Fig. 8 that the temperatures registered in the bedding plane and in the perpendicular direction exhibit similar behavior, but the temperature reached and the velocity of increase are different. In the parallel direction, the temperature increase is greater and faster than in the perpendicular direction. This observation was also made from other distance in the boreholes. This is due to anisotropic heat conduction: thermal conductivity is greater in the bedding plane than perpendicularly to it. This anisotropy was also seen on samples (Armand et al. 2017a, b) and has been numerically confirmed through TED data analysis (Garitte et al. 2014) (Table 1).

Fig. 8

\section{Heating stage $\mathrm{H} 1$} (TED1201)

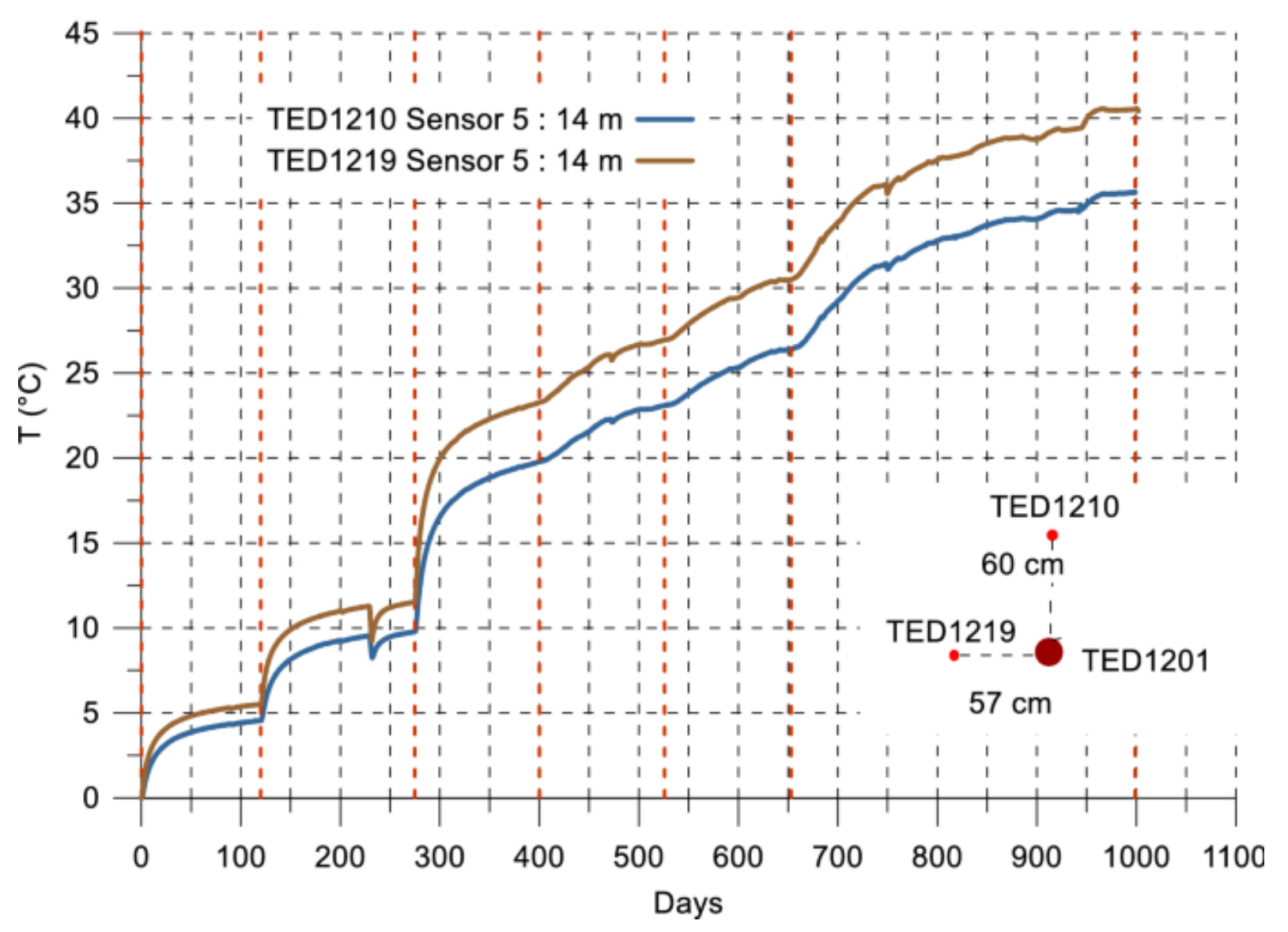

Heating stage $\mathrm{H} 2$ (3 heaters) 
Temperature history in boreholes TED1210 (perpendicular to the bedding plane) and TED1219 (in the bedding plane) at $14 \mathrm{~m}$ from the drift

Table 1 Summary of thermal conductivity values determined in laboratory on samples and by backanalyses on TED measurements ( $\lambda$ par: thermal conductivity parallel to the bedding plane (i.e. horizontal), $\lambda$ per thermal conductivity perpendicular to the bedding plane, Av. means average, Stdev. means standard deviation) (Armand et al. 2017a, b)

\begin{tabular}{|c|c|c|c|c|c|}
\hline & \multicolumn{2}{|c|}{$\lambda_{\mathrm{par}}(\mathrm{W} /(\mathrm{m} \mathrm{K}))$} & \multicolumn{2}{|c|}{$\lambda_{\text {per }}(\mathrm{W} /(\mathrm{m} \mathrm{K}))$} & \multirow[t]{2}{*}{$\lambda_{\text {par }} / \lambda_{\text {per }}$} \\
\hline & Av. & SD & Av. & SD & \\
\hline On sample (Jobmann et al. 2016) & 1.96 & 0.08 & 1.28 & 0.07 & 1.53 \\
\hline On sample from Andra & 1.89 & 0.05 & 1.26 & 0.04 & 1.50 \\
\hline Back-analysis (Jobmann et al. 2016) & 2.02 & & 1.37 & & 1.47 \\
\hline Back-analysis P3 (Garitte et al. 2014) & 1.88 & 0.17 & 1.26 & 0.13 & 1.51 \\
\hline
\end{tabular}

Another way to demonstrate the influence of the distance to the heater and of the direction with respect to the bedding plane is to show the horizontal and vertical temperature profiles at different times.

Figure 9 shows the increase of the temperature in function of the distance to the heater. The full square is the temperature variation on sensor located vertically to the heater (so perpendicularly to the bedding plane) and the empty square is the temperature variation on sensors located in the horizontally plane of the heater (so in the bedding plane). The square with a cross inside corresponds to sensors, which are neither vertically to the heater or neither horizontally. This figure highlights how the sensors closest to the heater gave the highest temperatures whatever is location. It also shows the anisotropic behavior of COx, indeed the variation of temperature on sensors located in the bedding plane is always higher than those located perpendicularly to the bedding plane whatever the distance to the heater. 
Fig. 9

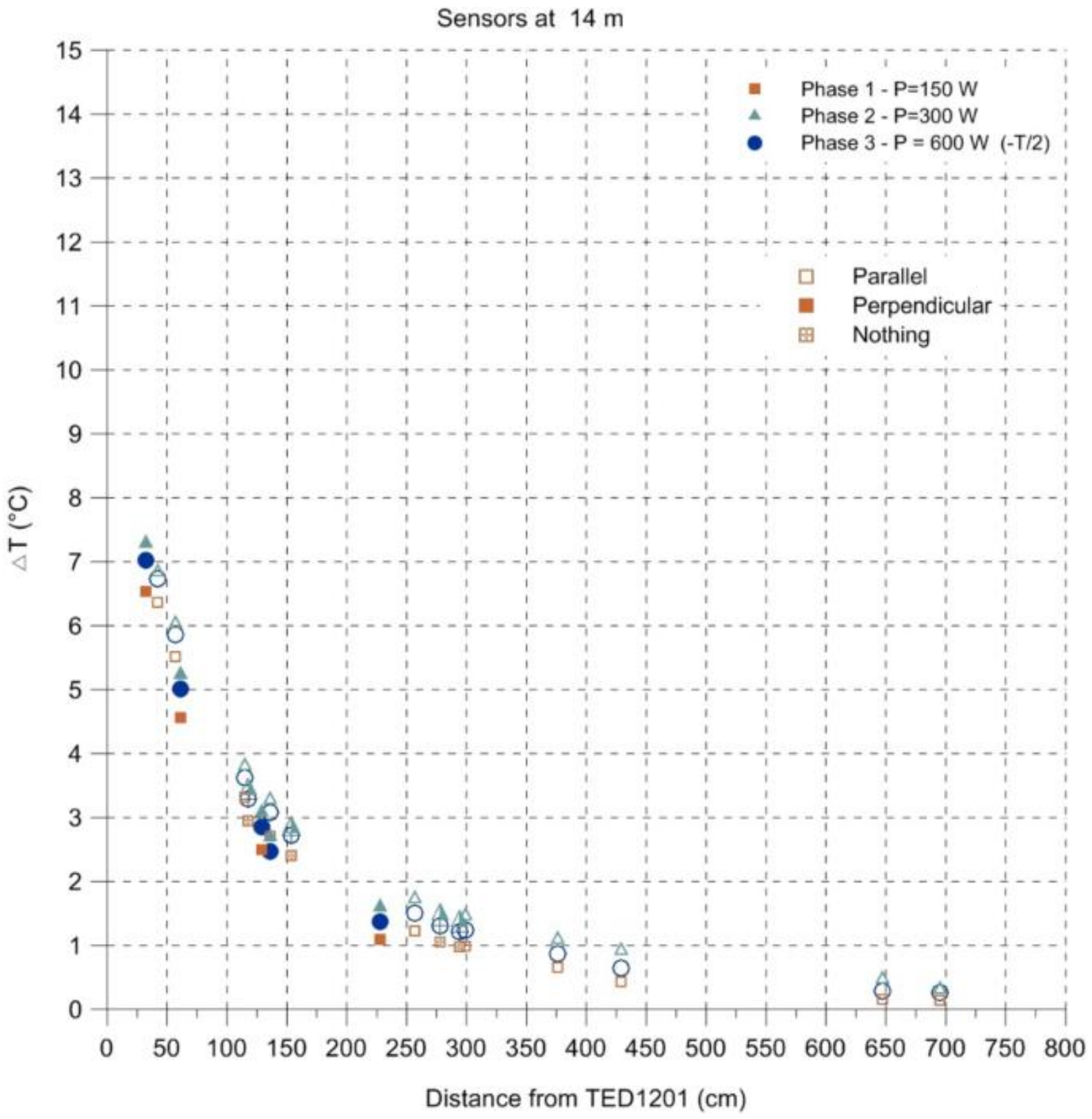

Temperature profiles along the bedding plane and perpendicularly to it at the end of each step of heating stage $\mathrm{H} 1$

Finally, it is proposed to study the evolution over time of the COx thermal response to the thermal load. For that purpose, Fig. 10a presents the temperature change history on sensor TED1217 in the 14$\mathrm{m}$ plane for each step of the second heating stage $\mathrm{H} 2$. The sensor is located in the bedding plane and at $29 \mathrm{~cm}$ from heater TED1202. 
Fig. 10

a
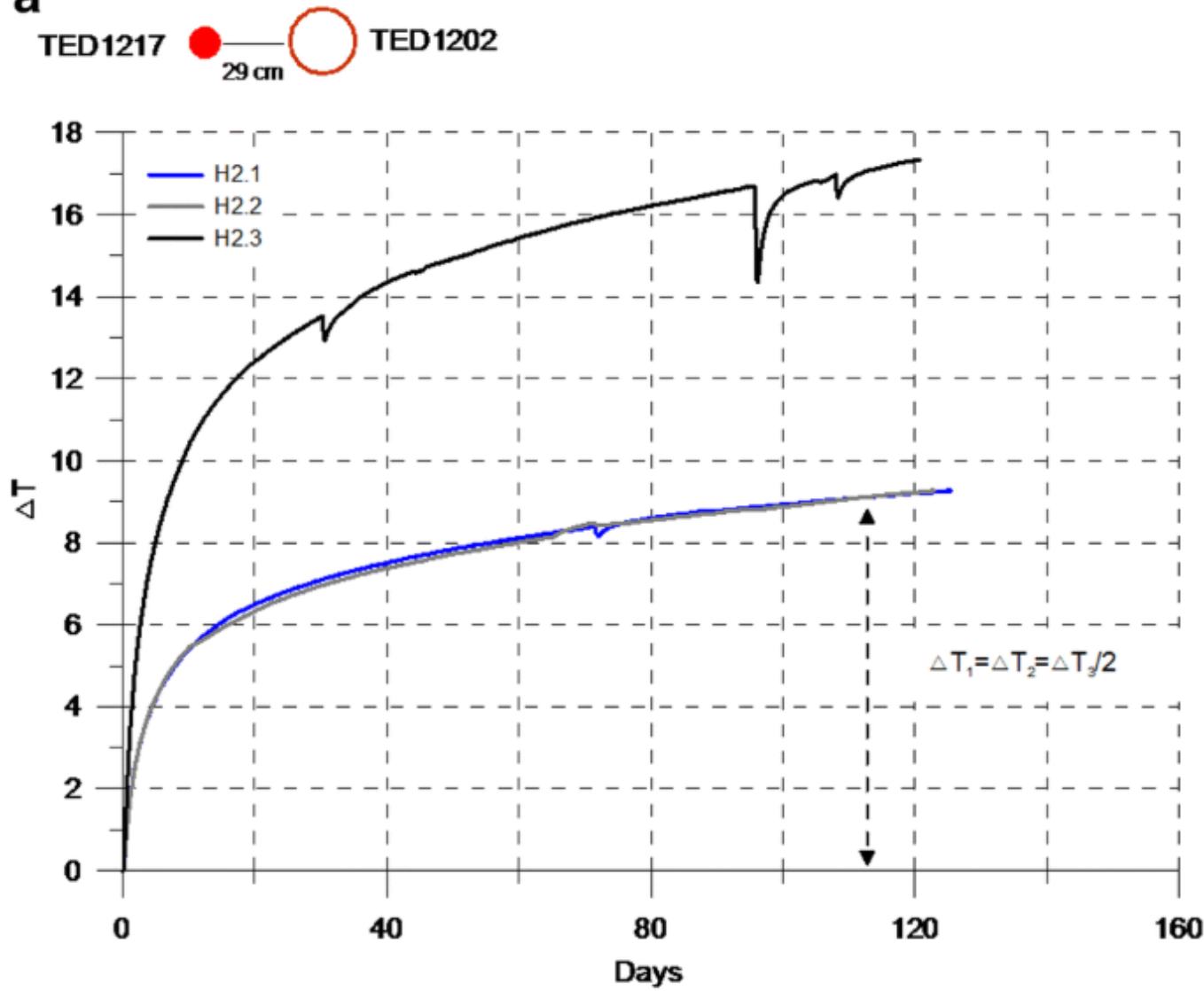

b
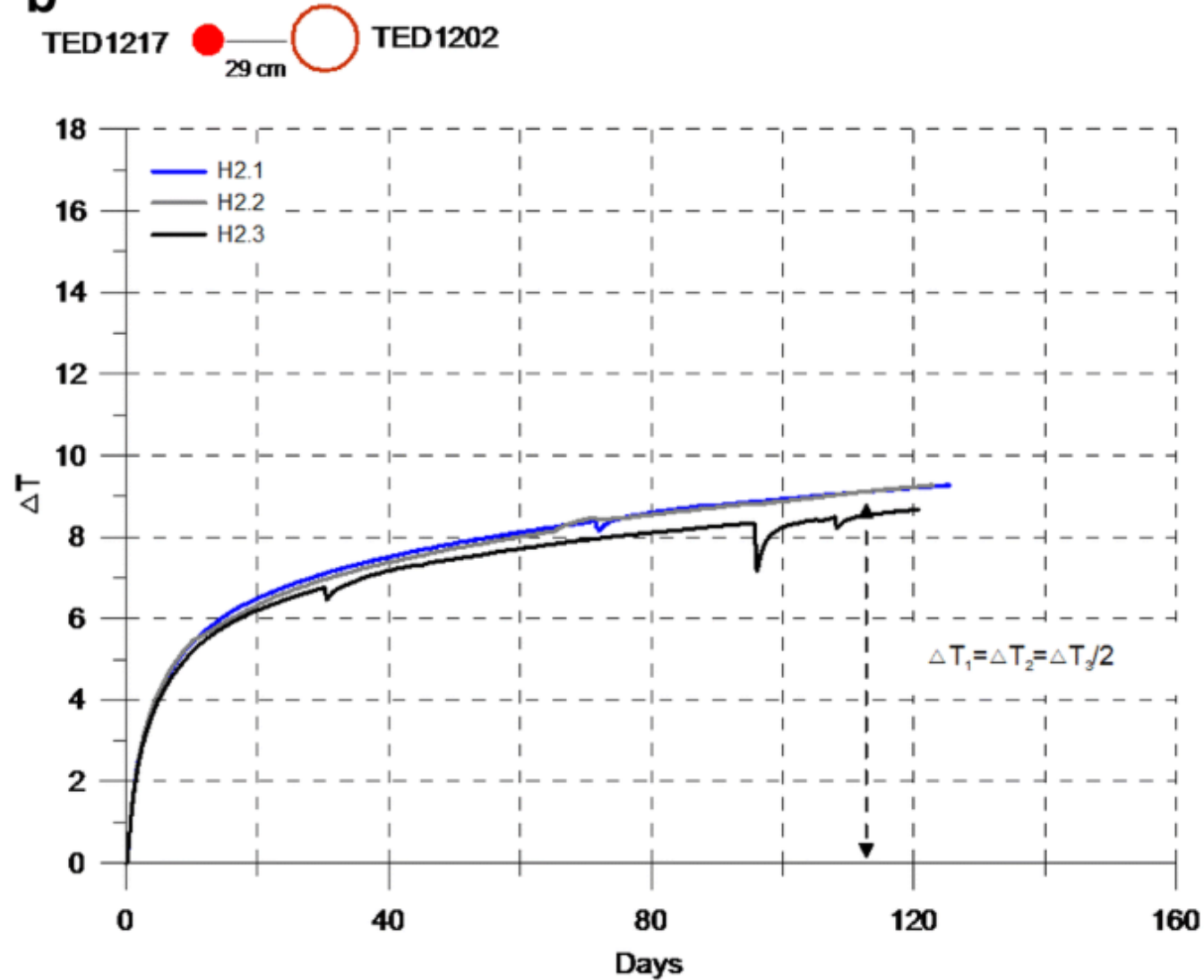
a Temperature changes $\Delta T$ in borehole TED1217 in the 14-m plane for each step of heating stage $\mathrm{H} 2$. b The temperature changes of the third step $\Delta T_{3}$ have been divided by two

Figure 10b represents the same evolutions as Fig. 10a except for the third step H2.3, where the temperature change has been divided by 2. Note that the power applied during steps $\mathrm{H} 2.1, \mathrm{H} 2.2$ and $\mathrm{H} 2.3$ was $150 \mathrm{~W}, 300 \mathrm{~W}$ and $600 \mathrm{~W}$, respectively. Analysis of the curves in Fig. 10 shows linear behavior: for a given amount of injected power, the temperature increase is the same. It should also be noted that the rate of increase remains very stable at each heating step. This shows that the thermal conductivity of the COx does not change with temperature in the range of the experiment.

\subsubsection{Temperature Variations in the GED Drift}

Temperature changes at the GED rock wall due to drift ventilation do not affect temperature field in the heating zone but are necessary to perform relevant 3D modeling of the TED experiment. To handle this boundary condition, temperature is recorded in the GED drift at $30 \mathrm{~cm}$ depth in the ground (TED1270-TED1277) and inside the drift (OHZ1290 and OHZ1291) from the start of heating (Fig. 11).

Fig. 11

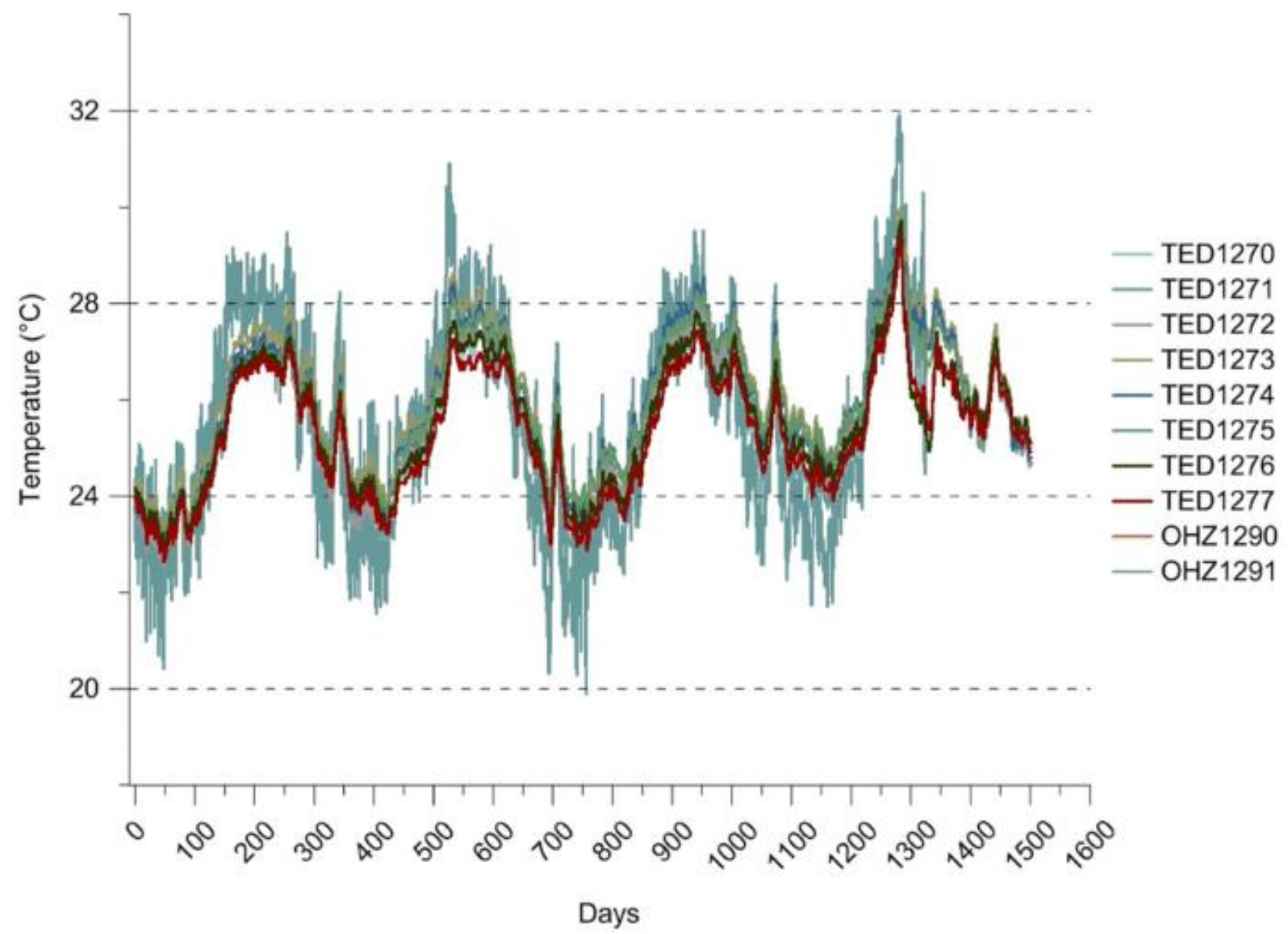

Temperature history recorded by the sensors in the GED drift at $30 \mathrm{~cm}$ depth in the ground inside the GED drift

These measurements are not affected by the heating. However, the influence of seasonal variations is very clear. The temperature of sensors TED1270-TED1277 ranges between 23 and $28^{\circ} \mathrm{C}$, all the sensors recording values close to each other (the maximum difference in temperature is about $1{ }^{\circ} \mathrm{C}$ ). 
This is consistent with the temperature evolution registered in the drift by sensors OHZ1290 and OHZ1291. However, the magnitude of the variation is much greater in these sensors because of ventilation and general activities in the drift. Temperature is at its lowest between January and April. Then, it rises to achieve a maximum value during summer.

\subsection{Analysis of the Hydraulic Response}

The pore pressure field is affected both by heating and the presence of surrounding openings (namely, the boreholes and the GED drift from which the boreholes were drilled) which may represent drainage surfaces. It was not possible in practice to guarantee perfectly non-draining boreholes. Thus, the impact of the presence of the GED drift and of the boreholes on the pore pressure field is studied in Sects. 4.2.1 and 4.2.2.

\subsubsection{Effect of the Drift}

To study the influence of the GED drift on the pore pressure field, the measurements recorded by boreholes TED1240 and TED1241 are used. They were located far from the heaters, at about $7 \mathrm{~m}$ and $6.5 \mathrm{~m}$ from heater TED1201, respectively, and far from all other instrumentation boreholes. Moreover, they included several piezometers ( 5 and 3 , respectively) at various depths.

Figures 12 and 13, respectively, show the pore pressures monitored in TED1240 and TED1241 since borehole excavation. They show the initial pore pressure gradient toward the drift, less disturbed by the thermal load or the presence of the other boreholes. For both boreholes, an increase of the monitored pressure with depth can be observed. It ranges from 22 bar at $5 \mathrm{~m}$ to 45 bar at $20 \mathrm{~m}$ on day 0 .

Fig. 12

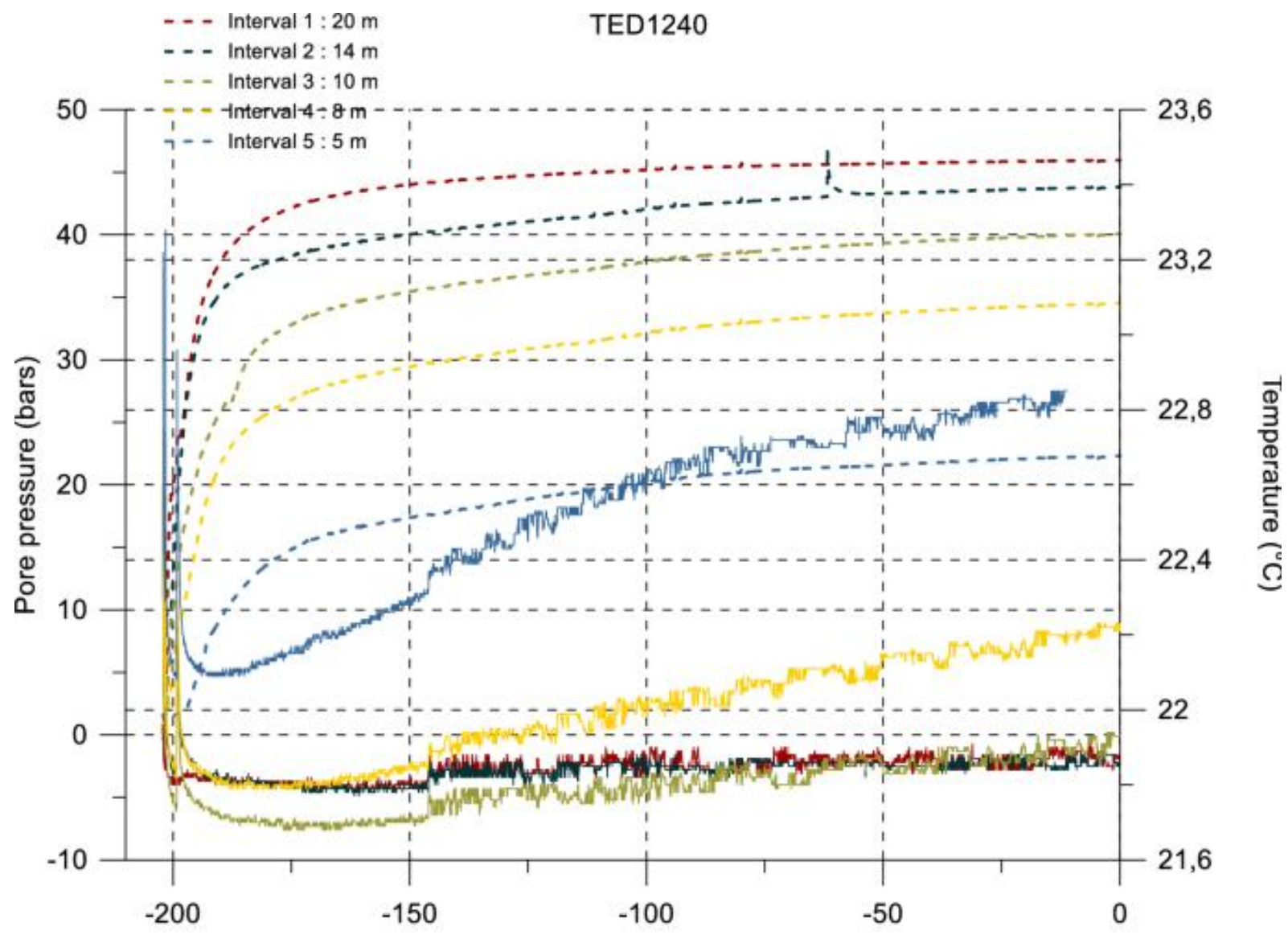

Days 
Measurements recorded in TED1240: temperature (bottom) and pressure (dotted line)

Fig. 13

TED1241

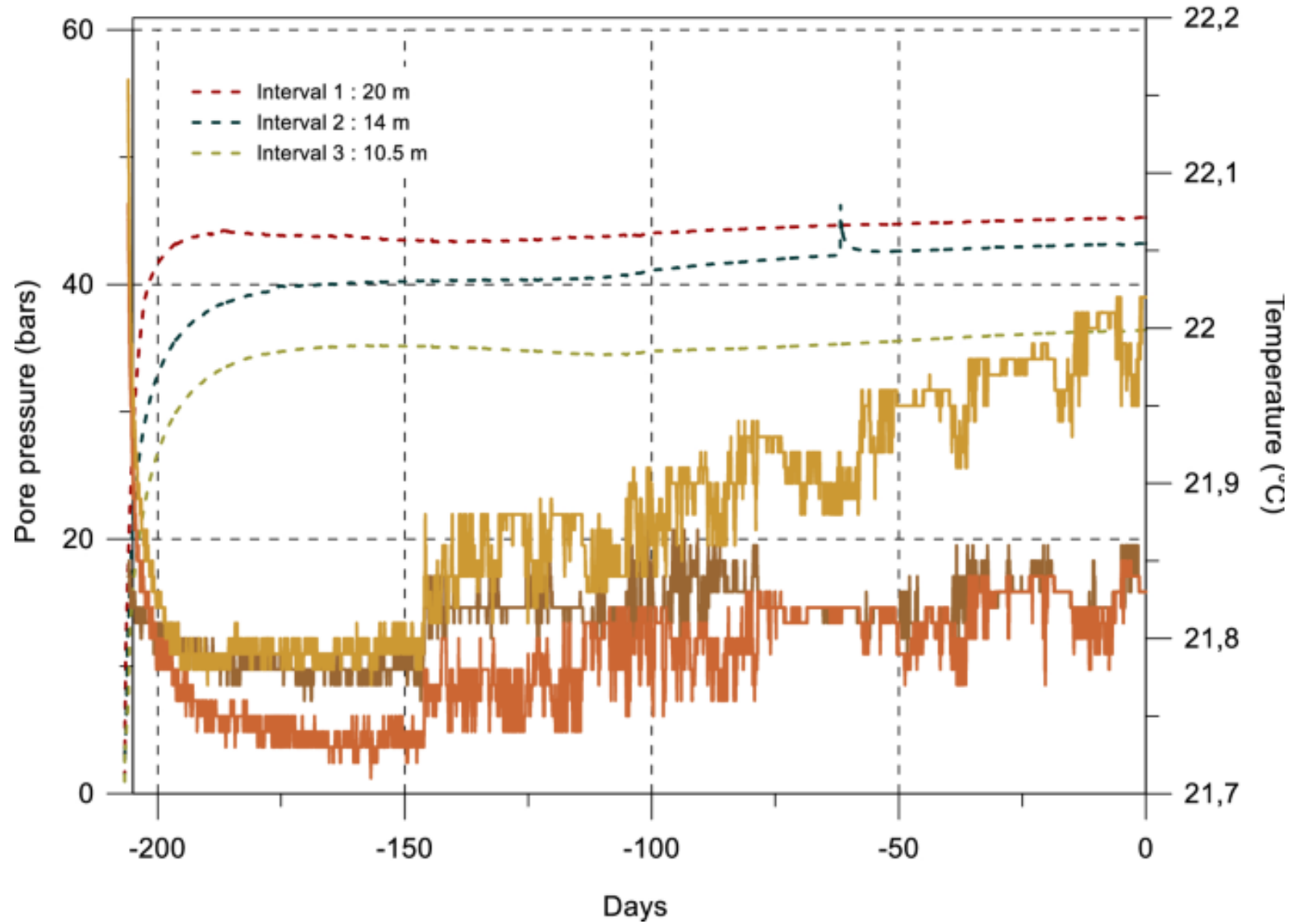

Measurements recorded in TED1241: temperature (bottom) and pressure (dotted line)

The physical mechanisms governing the hydraulic influence of the drift evolve with time. A short time after drift excavation, the pore pressures around the drift are influenced by the relaxation of mechanical stress due to the excavation. In the longer term, these pore pressures are only controlled by the drainage toward the drift.

Such observations are consistent with others in the URL. The difference in pressure between the intervals tends to decrease with depth (Armand et al. 2014).

\subsubsection{Effect of the Boreholes}

Figure 14 shows the pore pressure measured in piezometers TED1250-TED1259 from their installation until the beginning of heating. Several phenomena can be identified on this figure: 
Fig. 14

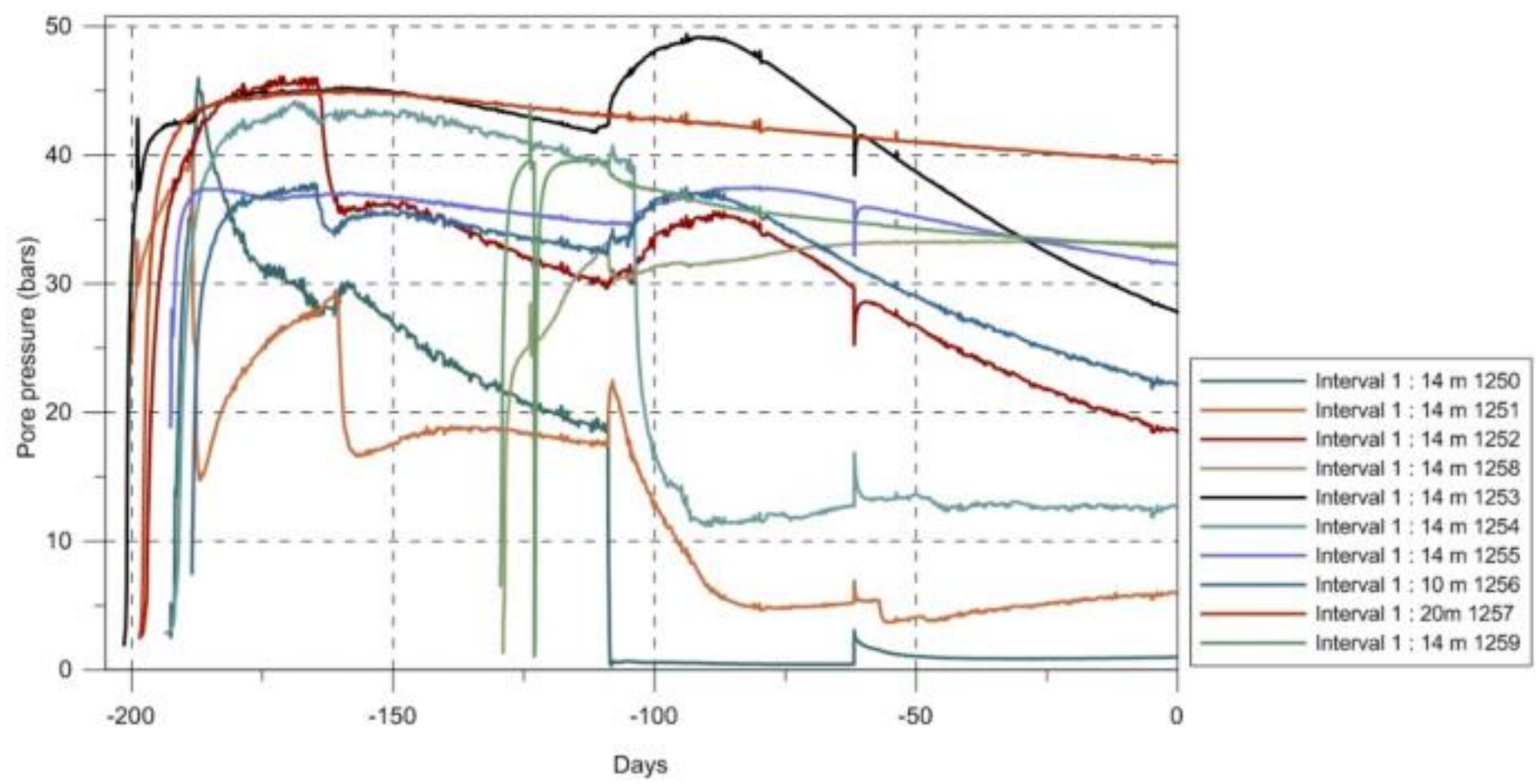

Pore pressure measured in TED1250-TED1259 after implementation of the boreholes and up to the first heating stage (day 0 )

- A pressure recovery phase after the implementation.

- Drilling of boreholes (extensometer, temperature and heating boreholes) (sudden increase or decrease in pressure).

- Hydraulic tests for permeability measurement (short pressure drops and rises).

- Rebalancing phase before heating (between day -62 and day 0 ).

These events are observable on the curves in Fig. 14.

Contrary to the pore pressures measured in TED1240 and TED1241 (located more than $6 \mathrm{~m}$ from the central heater), the pore pressures in most of the monopacker boreholes had not stabilized when heating started. These boreholes were impacted by the drilling of nearby boreholes, and more generally by their presence.

The major event observed on most of the boreholes corresponds to drilling of borehole TED1201, measured from day - 107. The interference is very clear for piezometer TED1250: the pressure in the chamber dropped abruptly to atmospheric pressure, probably indicating that this interval and borehole TED1201 are connected. No recovery is observed before the beginning of heating. A simultaneous pressure drop was observed in TED1251, TED1254, TED1258 and TED1259, while boreholes TED1252, TED1253, TED1255 and TED1256 initially reacted with a slow pressure increase followed by a decrease phase. These responses are correlated with the distance of the piezometers from the heater borehole. In the most remote boreholes, the effect appears with a delay of 2 or 3 days (TED1254 and TED1255) or does not appear at all (TED1257, which is located at $20 \mathrm{~m}$ depth).

As for the hydraulic influence of the drift, in the long term the mechanical effect of drilling dissipates whereas an important effect that can affect the pore pressure field is drainage. The backfilling in most 
of the instrumentation boreholes is likely to be water-tight. However, the system used for the two deformation measurement boreholes and the three heater boreholes (a metal tube surrounded by a concrete layer to fill the void between the casing and the rock) may not be as efficient in ensuring impermeability. Their presence locally affects the pore water pressure field. In particular, the pressure measured in TED1250 and TED1251 is certainly impacted by drainage through heater borehole TED1201 and extensometer borehole TED1230.

\subsection{Thermal Loading}

\subsubsection{Heating Phase}

To study the influence of the thermal load on pore pressure, Fig. 15 shows the pressure history in the ten monopacker boreholes from the start of heating. At each step, the temperature increase induced a pressure increase almost instantaneously due to differential thermal expansion of the water and the solid skeleton. Then, when the temperature increase rate decreased, the generated overpressures dissipated at a rate that depends on the hydraulic conductivity of the medium. Conversely, when the heater power reduced because of outages or during the cooling stage, the induced decrease in pore water volume led to a pressure drop. As mentioned earlier, this drop was particularly large at day 229 in boreholes TED1251 and TED1250, the closest boreholes to the central heater, which fell to $0 \mathrm{MPa}$ because of a 48 -h-long outage.

Fig. 15

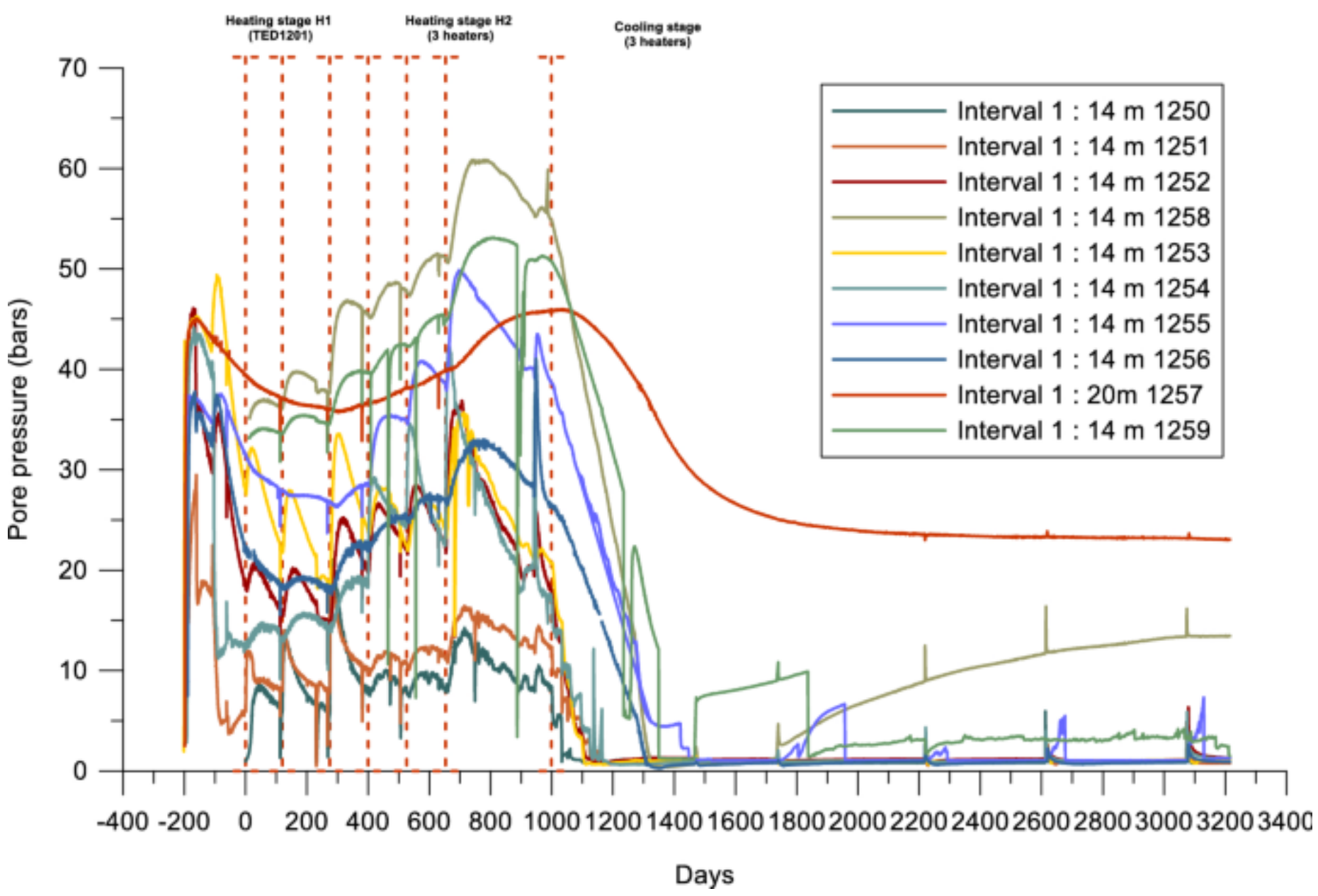

Pore pressure history recorded by monopacker boreholes TED1250-TED1259 
Moreover, it should be noted that the greater the change of temperature, the stronger the pressure reaction observed (see the difference for each sensor between heating steps H1.3 and H1.2 for example). As for the thermal response, the pressure change depends on the distance between the sensor and the heater. Boreholes TED1252, TED1253 and TED1254 are interesting to illustrate this. The pore pressures in these sensors were very close at the start of the second heating stage $(\mathrm{H} 2)$. However, the pore pressure increase was greater in piezometer TED1254, located closer to a heater (TED1202) than in the other two piezometers. Regarding this, note that the influence of thermal load on pore pressure is very clear for the eight monopacker boreholes located in the 14-m plane whereas it is less pronounced in boreholes TED1256 and TED1257, at 10.5 and $20 \mathrm{~m}$ deep respectively. These sensors were farther from the heaters and therefore observed more limited temperature variations (Fig. 7).

Observations of pore pressure also show that its evolution depends on sensor location with respect to the bedding plane. This phenomenon is shown in Fig. 16. It presents the overpressure triggered at the third power step (H1.3) in boreholes TED1253 and TED1258, located parallel and perpendicular to the heater, respectively, and at $115 \mathrm{~cm}$ and $136 \mathrm{~cm}$. It appears that the pore pressure peak was reached faster in TED1253 than in TED1258 (day 26 and day 55, respectively). Moreover, in the very short term after the power step, a difference in behavior is very clear. At borehole TED1258, the pressure increase was instantaneous after the power step and appeared even earlier than the temperature increase. This delay in temperature response can be observed at the most remote boreholes (e.g. TED1252, TED1253, TED1254, TED1258 and TED1259) but not at those that were very close to a heater such as TED1250. In contrast, just after the power step, the pore pressure in TED1253 decreased first, while no temperature change was recorded (see zoom on the first 10 days on Fig. 16). Finally, when temperature started rising in the borehole, pore pressure also increased. 
Fig. 16
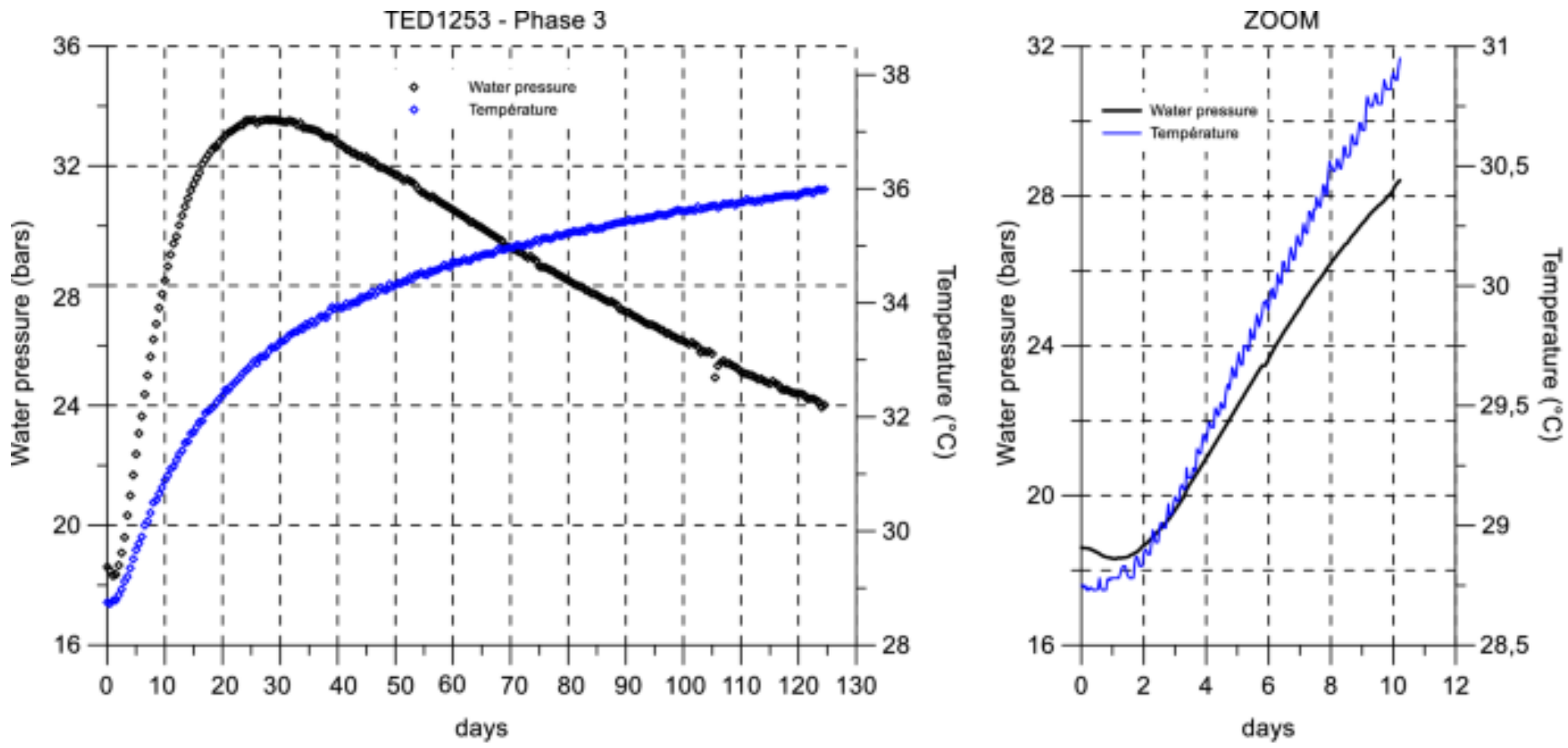

$\mathbf{a}$

TED1258 - Phase 3

ZOOM
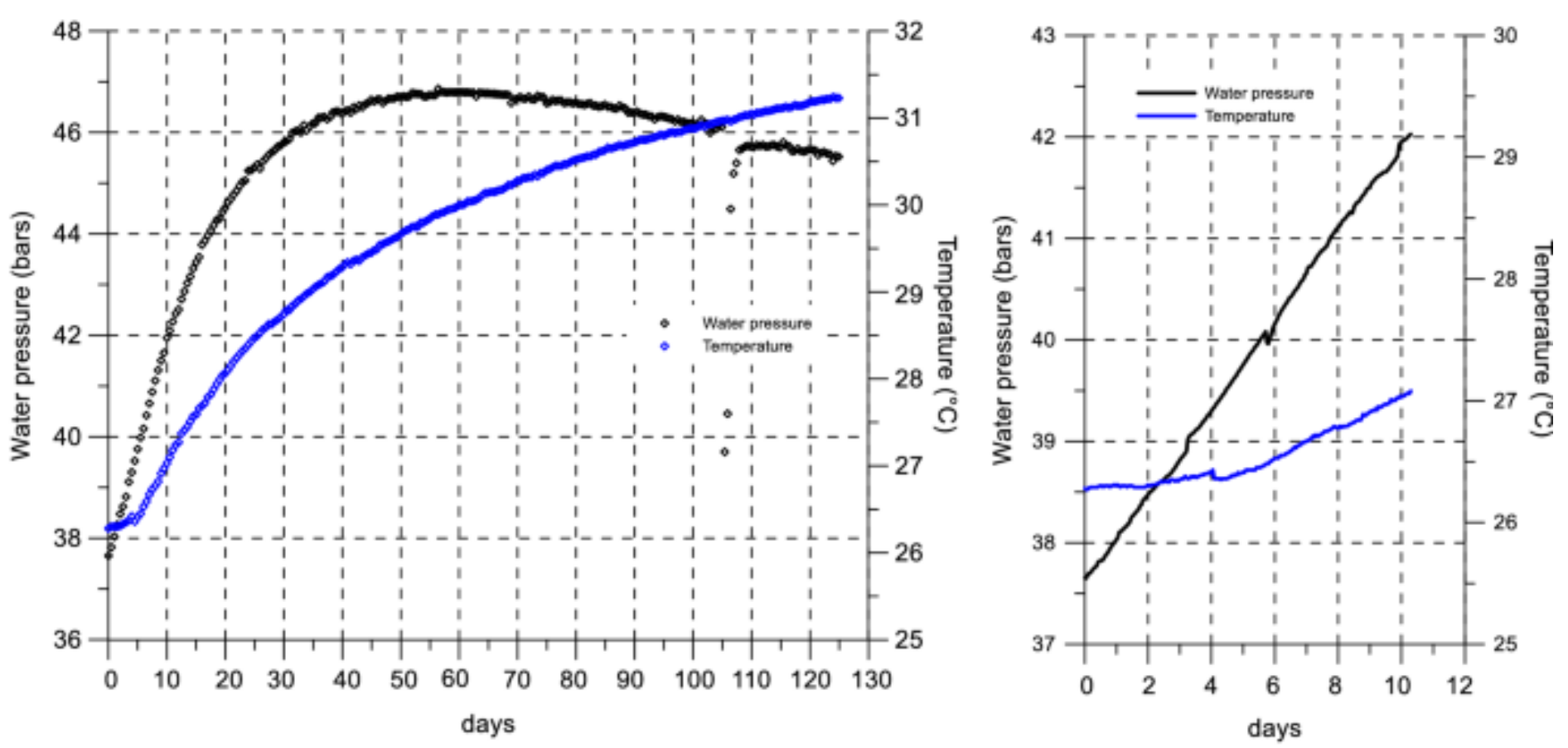

b

Pressure and temperature monitored in boreholes a TED1253 and b TED1258 during the first 130 days of the third heating step of the first stage $(\mathrm{H} 1.3, \mathrm{P}=600 \mathrm{~W})$-zoom on the first 10 days

This phenomena is explain by Garitte et al. (2010) by the anisotropic behavior of the rock. At a given moment just after the start of heating, there are two distinct areas around the heater (Fig. 17). Directly 
adjacent to the heater, there is a heated area (in grey on Fig. 17) which is in extension due to thermal expansion. In reaction, the surrounding area, where the temperature has not yet increased, is compressed in the radial direction and extended in the orthoradial direction. Moreover, knowing that the parallel-to-bedding stiffness of the COx is greater than its perpendicular-to-bedding stiffness, it can be assumed that the vertical strain is greater than the horizontal one. Therefore, parallel to the bedding the pressure decreased (expansion) and it increased in the perpendicular direction (compression). The instantaneous pressure response is related to this hydro-mechanical loading and reflects how the mechanical behavior is anisotropic.

Fig. 17

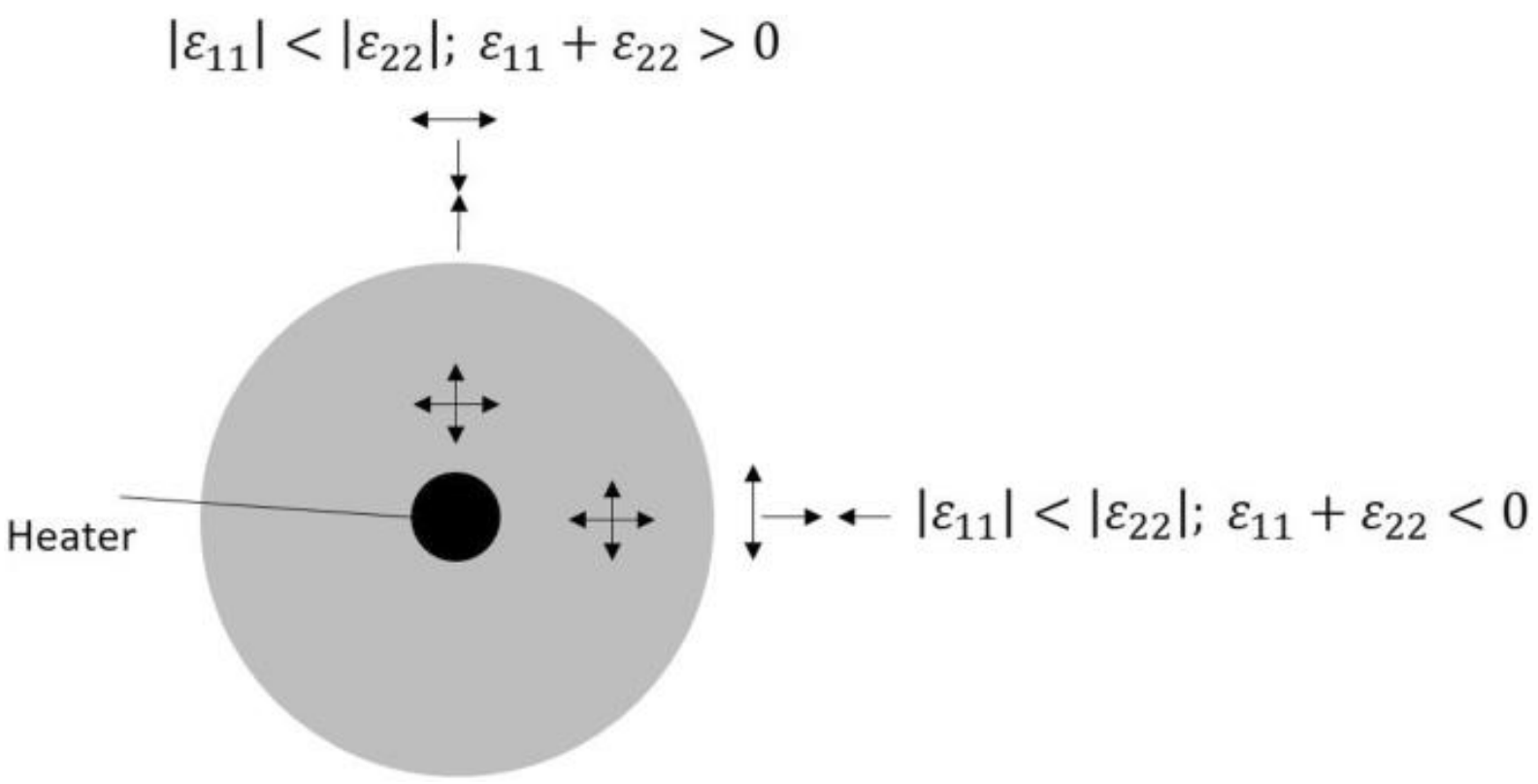

Schematic view of the strains during the heating phase (grey area = heated area, white area = nonheated area)

Finally, as for the study of the thermal response, the evolution of the pressure response to the thermal load is analyzed here. To that end, Fig. 18 shows the overpressures and temperature changes triggered in boreholes TED1250 and TED1254, respectively, during steps H1.3 and H2.3. Both sensors were located close to a heater (less than $40 \mathrm{~cm}$ ) and perpendicular to the bedding. In both cases, the power applied by the adjacent heater was the same and equal to $300 \mathrm{~W}$. As expected, the temperature changes were essentially identical. However, the overpressure recorded by TED1254 (in black on Fig. 18) was significantly higher than the one recorded by TED1250 (in brown on Fig. 18). As previously mentioned, the pore pressure increase due to a heating load relates to the difference between the thermal expansion coefficients of pore water and of the solid skeleton. As a result, it seems that a reasonable explanation for the differences between the overpressures reached in TED1254 and TED1250 is first the variation of the thermal expansion coefficient of water with temperature, knowing that the initial temperature in TED1250 at the beginning of the step was $36^{\circ} \mathrm{C}$ whereas it was $44{ }^{\circ} \mathrm{C}$ in TED1254. For comparison, at $1 \mathrm{MPa}$, the volumetric thermal expansion coefficient of pure water is $3.50 \times 10^{-4} \mathrm{~K}^{-1}$ at $36^{\circ} \mathrm{C}$ and $4.11 \times 10^{-4} \mathrm{~K}^{-1}$ at $44^{\circ} \mathrm{C}$ (Spang 2002). Second, at higher temperature the induced thermal stress will be also higher and then contribute to the increase in pore pressure. 
Fig. 18
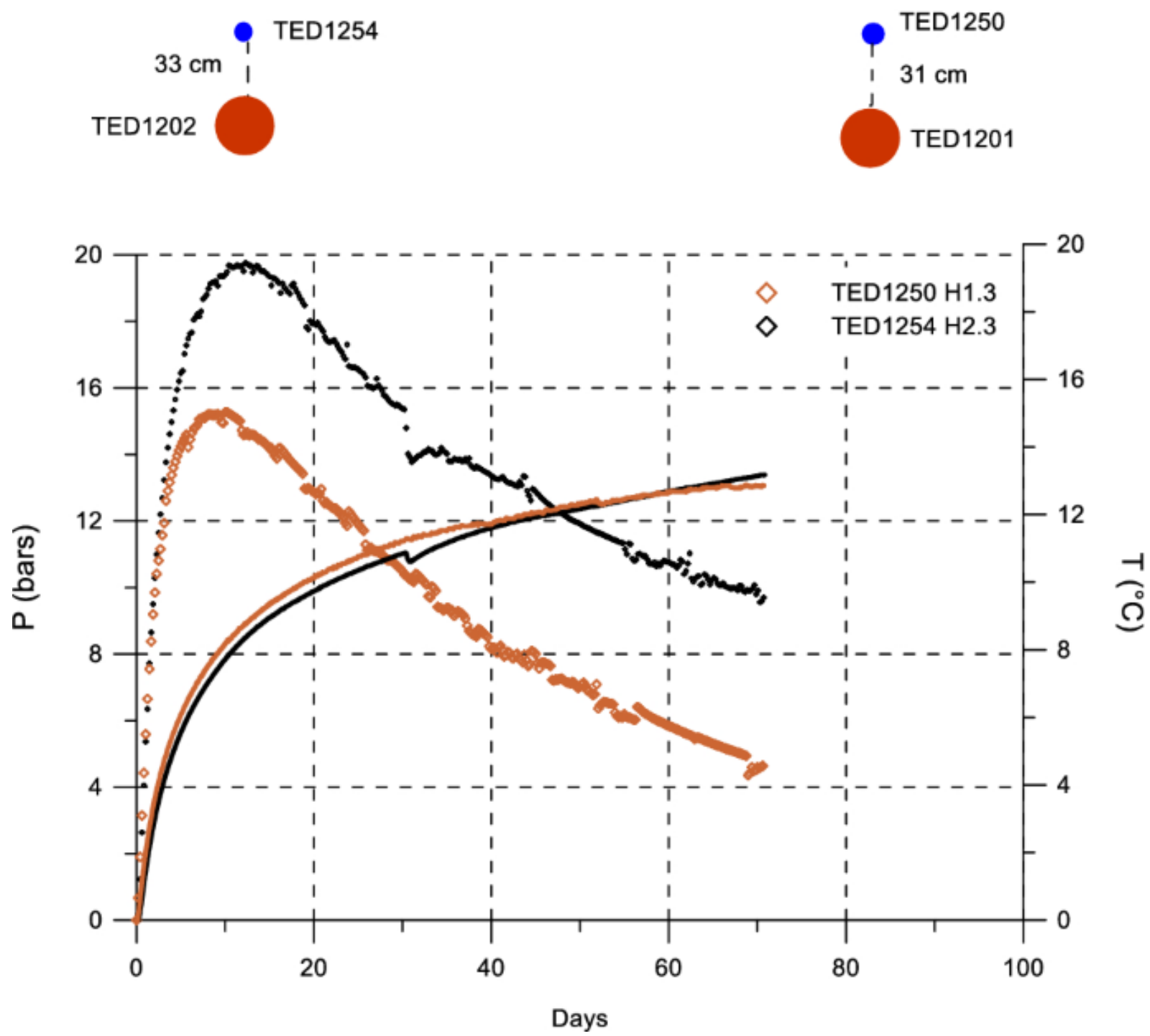

Overpressures and temperature changes triggered in boreholes TED1250 (in brown) and TED1254 (in black) during steps $\mathrm{H} 1.3$ and $\mathrm{H} 2.3$, respectively

It has also already been mentioned that after the peak, the pressure diffusion rate is controlled by the hydraulic conductivity of the medium. Figure 19 shows the overpressures triggered in borehole TED1252 during the three steps of the second stage $\mathrm{H} 2$, along with the temperature changes. It appears that the pressure diffusion rate increases with time. This behavior is attributed to the decrease in water viscosity with temperature, which leads to a small increase in hydraulic conductivity. This increase does not reflect any damage of the rock. 
Fig. 19
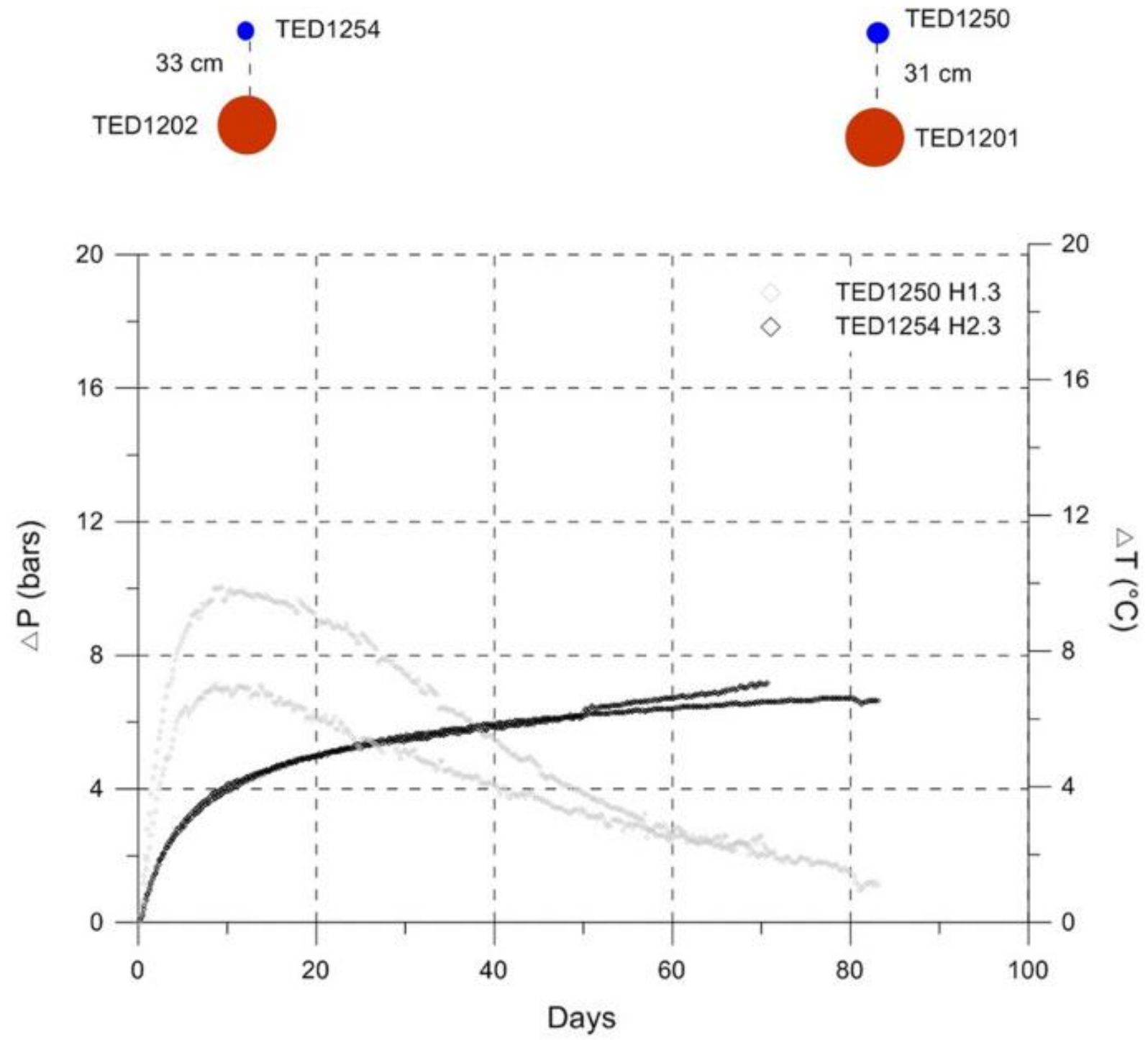

a Overpressures and $\mathbf{b}$ temperature changes in borehole TED1252 during the three steps of second heating stage $\mathrm{H} 2$

\subsubsection{Cooling Phase}

The cooling phase started in October 2012 (999 days). The power supplied by the heaters was decreased by steps of $50 \mathrm{~W}$ every month, until the final shutdown on day 1271 . Prior design simulations using the Finite Element Method (FEM) program Code_Bright showed that an abrupt shutdown would have led to a very rapid decrease of pore pressure until suction and hence to loss of information in the piezometers. On this basis, the 50-W/30-day strategy was preferred. To illustrate, the various scenarios which were tested are presented in Fig. 20; no cooling at all in TED_C1, in TED_C2 cooling by 50-W steps at 30 days intervals and in TED_C3 cooling is via two steps of $300 \mathrm{~W}$ and $150 \mathrm{~W}$ at 120 days intervals. 
Fig. 20

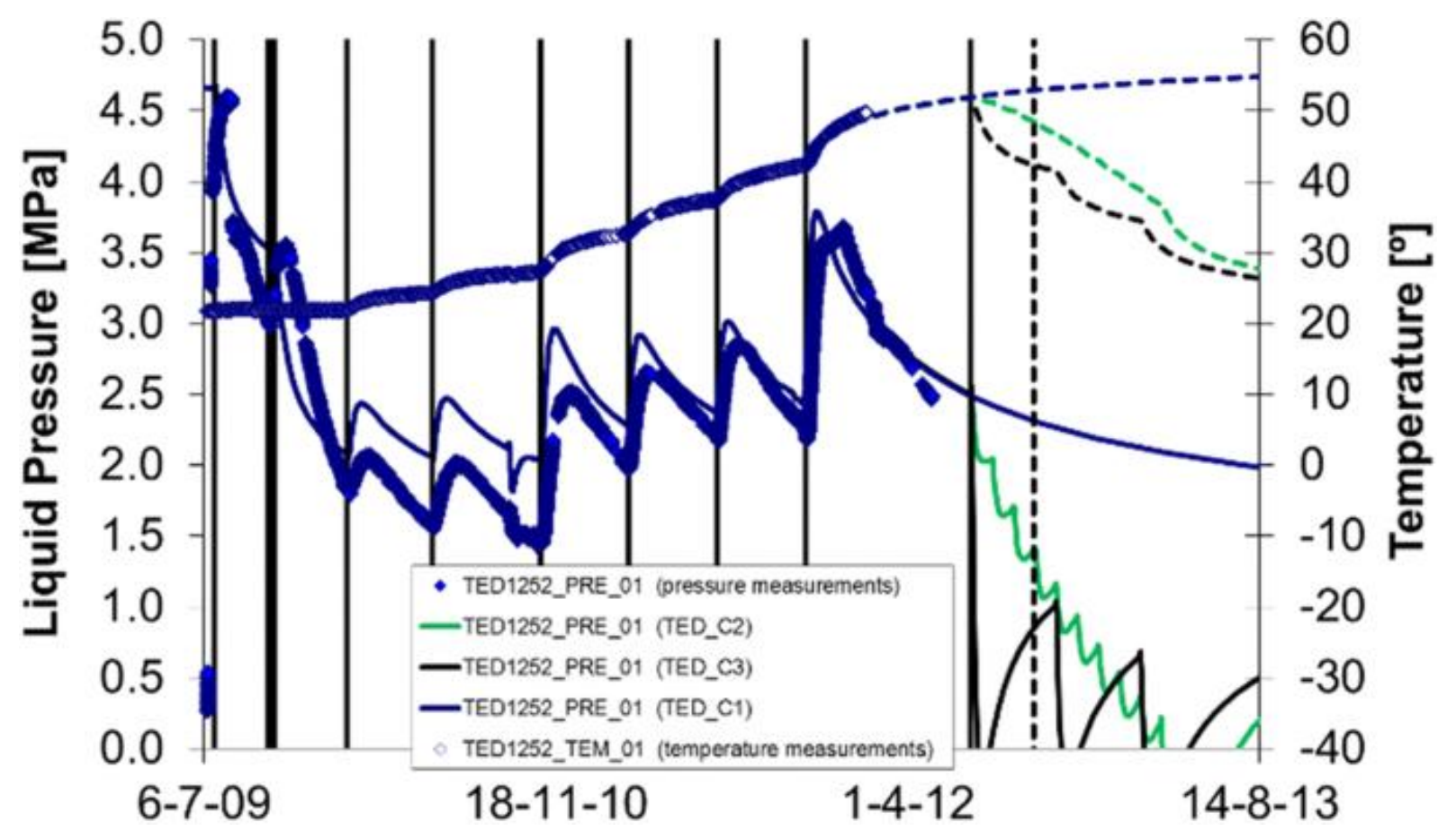

Measured pore water pressure and temperature in borehole TED1252 compared with simulation performed by UPC for the cooling phase design. TED_C1 (no cooling), TED_C2 (by steps of $50 \mathrm{~W}$ at 30 day intervals) and TED_C3 (two steps of $300 \mathrm{~W}$ and $150 \mathrm{~W}$ at 120 day intervals)

As expected, it was observed by calculation in all monopacker boreholes that the pressures are in suction at the end of the cooling stage (Figs. 15, 20). A possible explanation is that a rapid cooling reduces both the pore pressure and the stress confining. The first one is due essentially to the thermal contractions of solid and water during cooling. The second one induces a volumetric strain increment in extension. Both factors could provoke a negative pore pressure. The thermo-poro-elastic simulation confirmed this explanation.

The cooling down phase for the three heaters of the TED experiment is shown in Fig. 5.

\subsubsection{Pressurization Coefficient}

According to Eq. (1), it is possible to define $\Lambda *$, the thermo-mechanical pressurization coefficient including the contribution of the term $B \Delta \sigma \mathrm{m}$

$\Lambda *=\Delta \mathrm{p} / \Delta \mathrm{T}$.

In the TED experiment, this coefficient was estimated from the experimental data and from numerical data presented in Fig. 24.

The numerical simulation of TED experiment was performed in COMSOL Multiphysics software and a thermo-poro-elastic approach was used. We briefly describe the numerical simulation since this is not the main objective of this paper. The model geometry consists in representing half of GED drift $(2.3 \mathrm{~m}$ radius), three heater boreholes (TED1201, TED1202 and TED 1203) and two extensometer boreholes (TED1230 and TED1231). The extensometer boreholes were considered since it was observed that their presence was a source of drainage and consequently affected the pore pressure field. TED1201, TED1202, TED 1203, TED1230 and TED1231 are modeled as porous materials with a permeability 
higher than that of host rock. Other boreholes, that are considered watertight, are not explicitly represented in the model. The domain consists in a cube with a side length of $50 \mathrm{~m}$ at $490 \mathrm{~m}$ depth (see Fig. 21).

Fig. 21

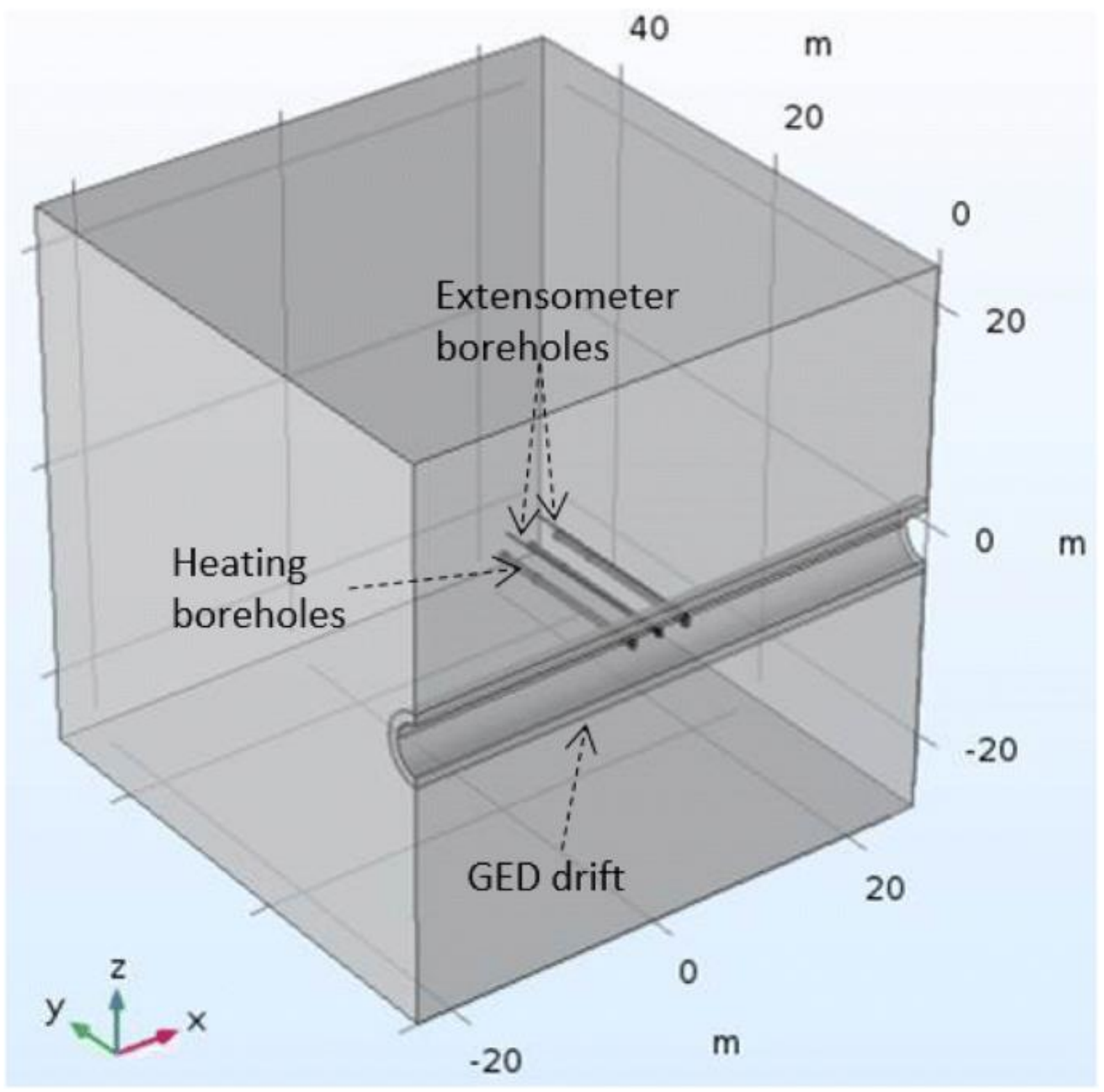

Geometry model of TED experiment modeling

The numerical simulation follows several phases from GED drift excavation to TED experiment. It includes

- Generation of initial state: $22{ }^{\circ} \mathrm{C}$ of temperature; $4.7 \mathrm{MPa}$ of pore pressure, $12.4 \mathrm{MPa}$ of horizontal minor stress (x-axis direction); $12.7 \mathrm{MPa}$ of vertical stress and $16.1 \mathrm{MPa}$ of horizontal major stress ( $y$-axis direction);

- Excavation of GED drift;

- Draining process toward GED drifts until before TED experiment; 
- Excavation of heating boreholes (TED1201, TED1202 and TED 1203) and the extensometer boreholes (TED1230 and TED1231) and continue the drainage modeling;

- Activation of the heat power on the heaters as described in Fig. 4.

The first four steps allow to obtain a nearly pore pressure state before heating in comparison to the observation. Thermo-hydro-mechanical parameters are calibrated by adjusting the numerical data to the experimental ones. Concretely, the comparison between the numerical solution and the measurement data was carried out at six sensors TED1210_TEM_05, TED1219_TEM_05, TED1250_TEM_01, TED1251_TEM_01, TED1253_TEM_01 and TED1258_TEM_01 for thermal parameters (see Fig. 22) and at two monopacker boreholes TED1253 and TED 1258 for hydromechanical properties (see Fig. 23).

Fig. 22

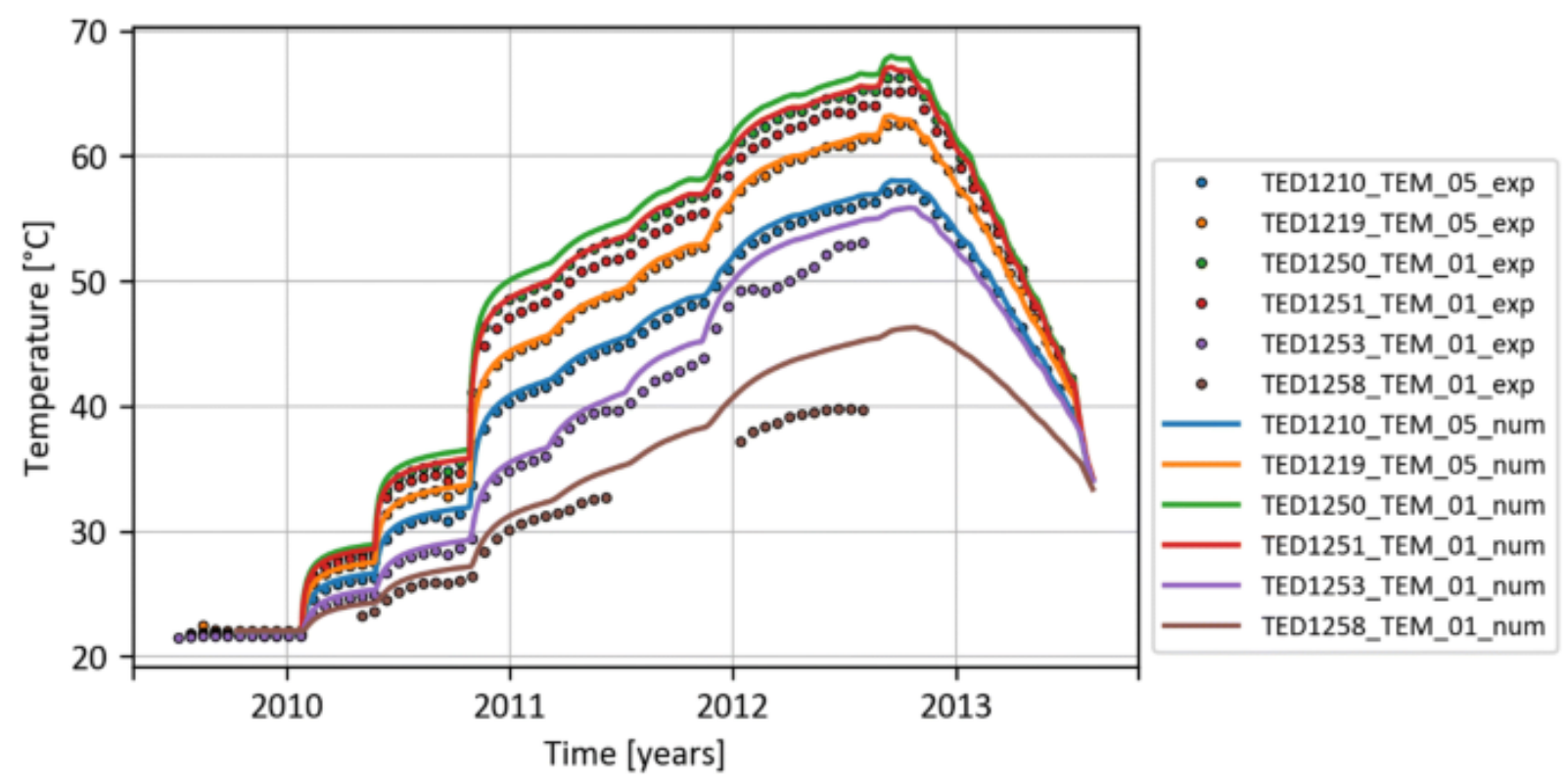

Comparison between numerical solution and measurement data of temperature variation at TED1210_TEM_05, TED1219_TEM_05, TED1250_TEM_01, TED1251_TEM_01, TED1253_TEM_01 and TED1258_TEM_01 
Fig. 23

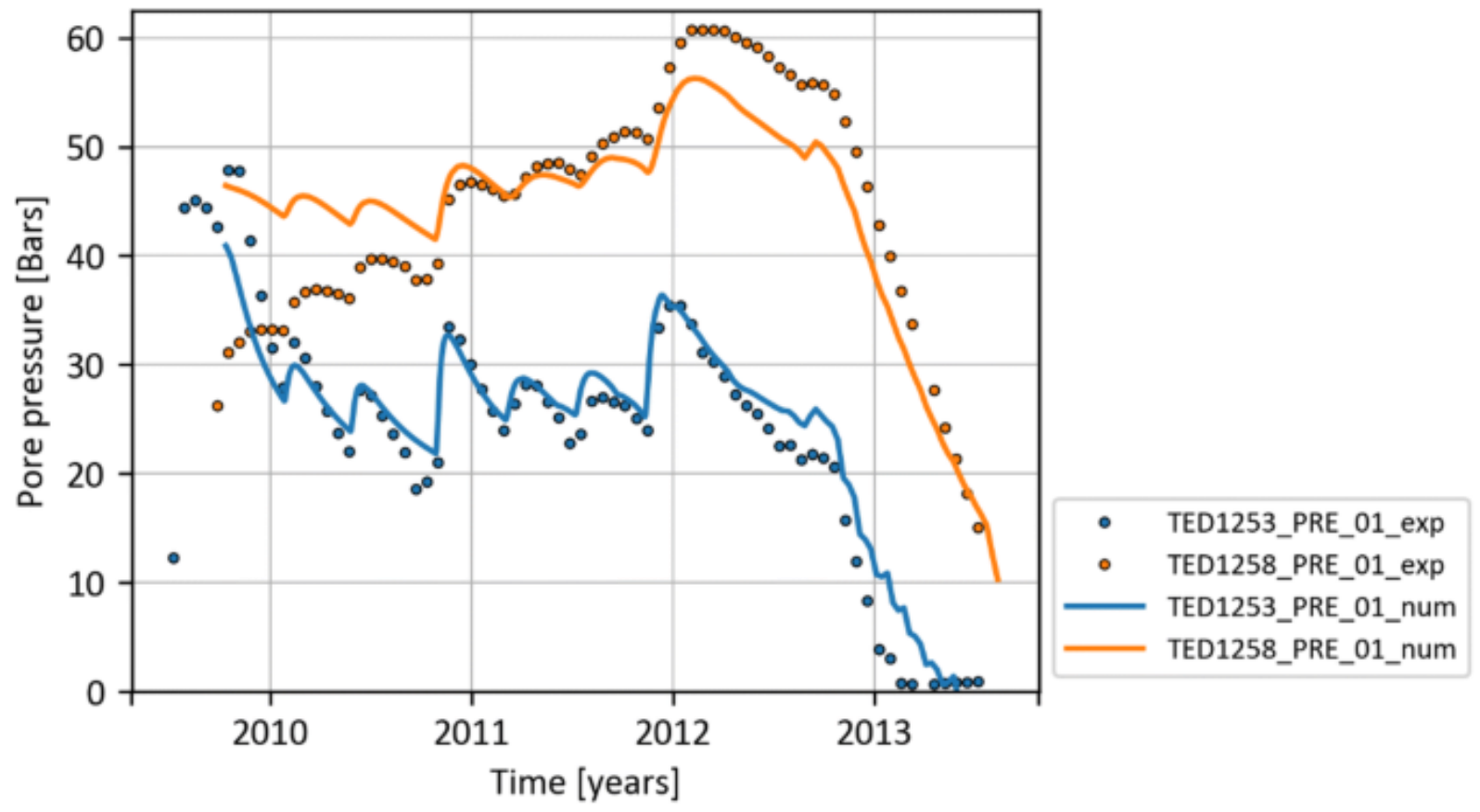

Comparison between numerical solution and measurement data of pore pressure variation at TED1253 and TED1258

Figure 24 shows the variation of temperature (TED125x_T), pore pressure ((TED125x_P) and total mean stress (TED125x_S) with time. It is noted that an increase in temperature induces an increase in both the pore pressure and total mean stress. Inversely, the pore pressure and the total mean stress decrease during the cooling phase. The numerical simulation confirms that the total mean stress contributes to the pore pressure increase in the field heating experiment. This numerical result allows to calculate the thermo-mechanical pressurization coefficient and compares them to experimental data calculation as shown in Fig. 25. 
Fig. 24

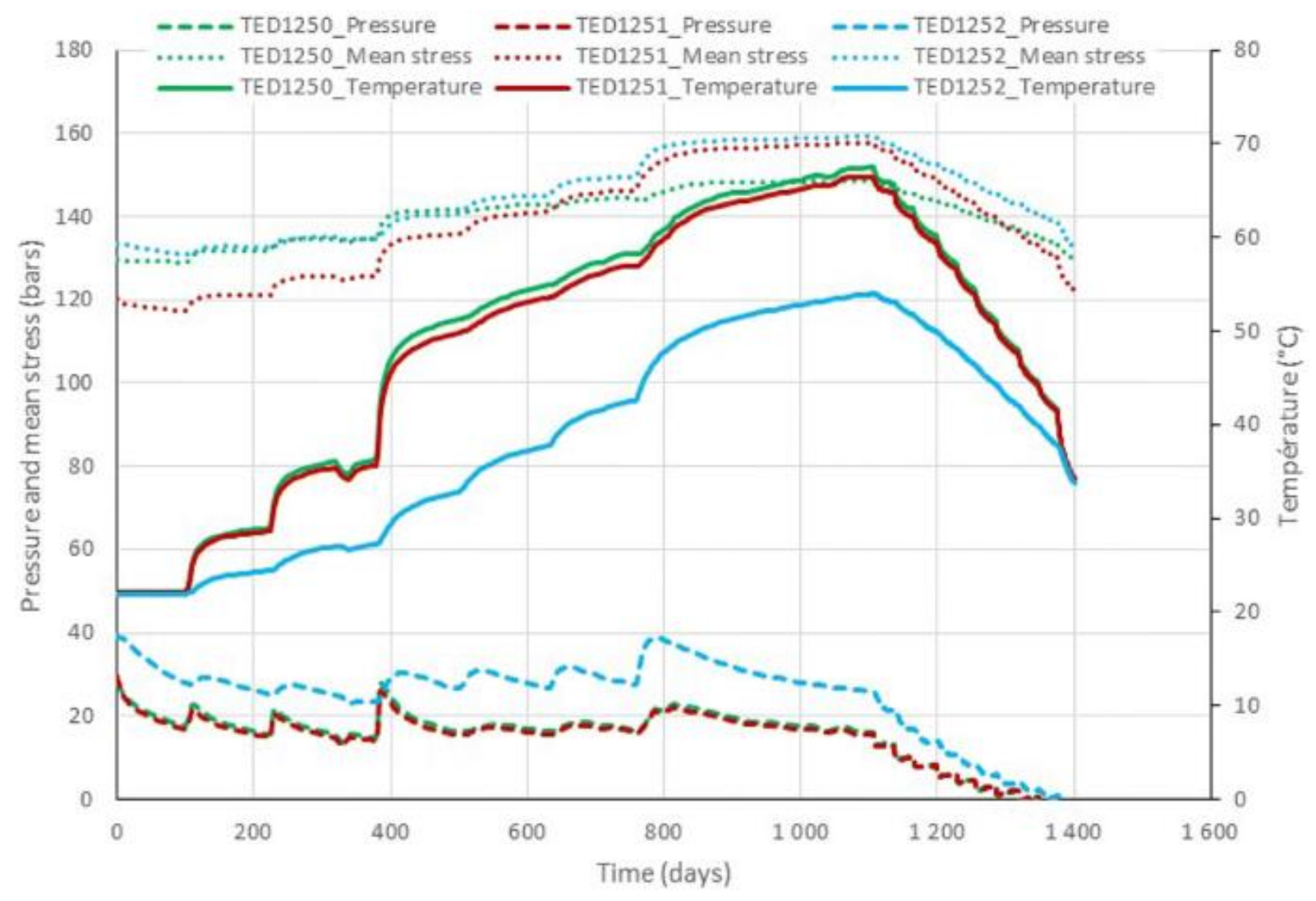

Simulation of the TED experiment: Evolution of temperature, pore pressure and total mean stress at sensors TED1250, 1251 and 1252 
Fig. 25

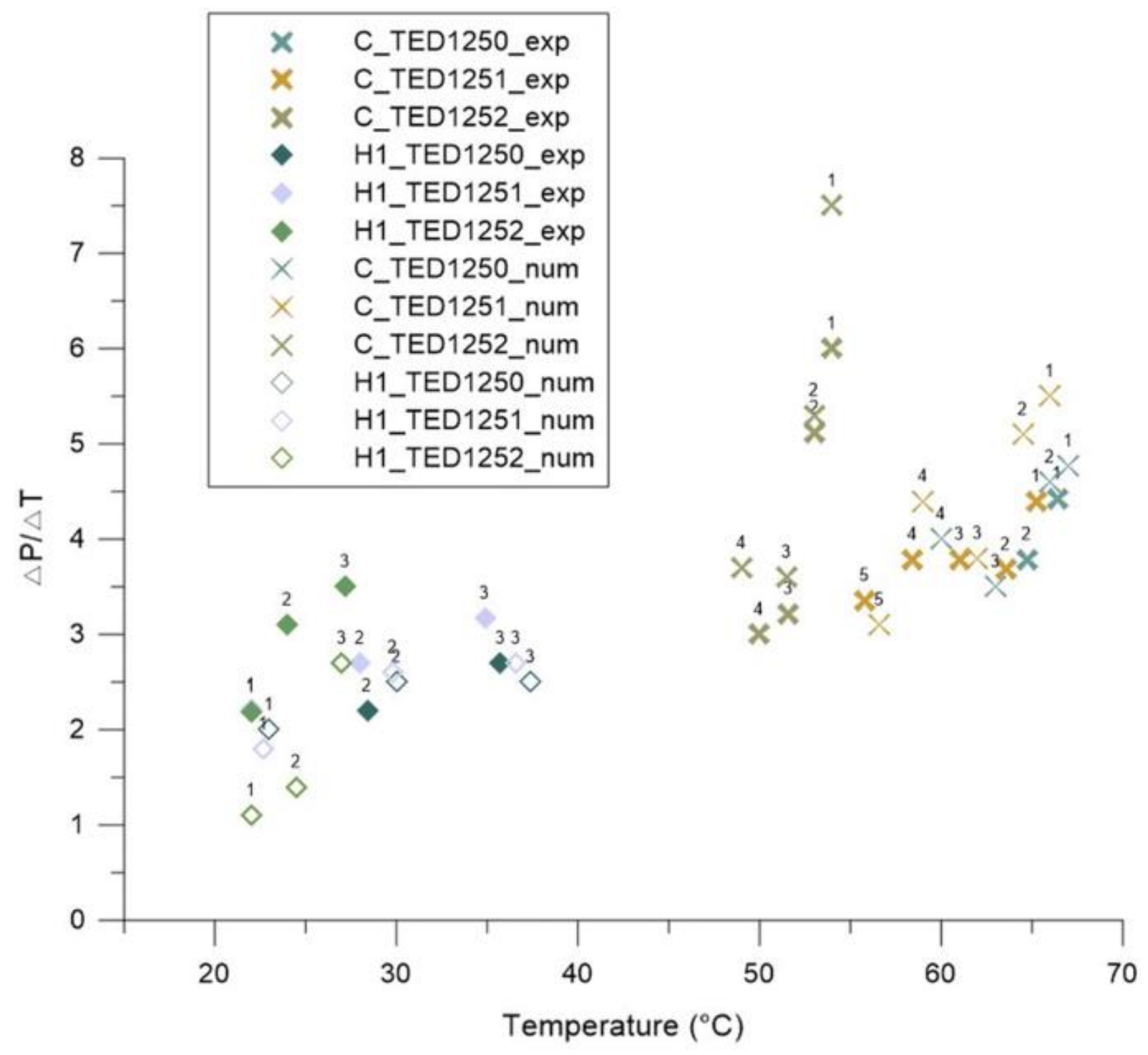

Coefficient $\Delta p / \Delta T$ calculated from measurement and from simulation data at sensors TED1250, TED1251 and TED1252

The pressurization coefficients determined in the three boreholes TED1250, TED1251 and TED1252 during the first heating phase $(\mathrm{H} 1.1, \mathrm{H} 1.2, \mathrm{H} 1.3)$ and during the cooling phase are shown in Fig. 25. From both cases, experimental and numerical data, the coefficient $\Delta \mathrm{p} / \Delta \mathrm{T}$ was obtained as the early slop of the curve representing pressure variation as a function of the temperature in the thermal phase. In Fig. 25, the full signs represent the coefficient obtained from experimental data and the empty signs the coefficient obtained from numerical data. The square is the coefficient obtained during the cooling phase (C) and the triangle during the heating phase $(\mathrm{H})$. The different phases are represented by their number above the corresponding signs. There is one different color for each borehole.

Overall the coefficient $\Delta p / \Delta T$ increased during the heating phase whereas it decreased during the cooling phase. This is due to the thermal expansion coefficient of water being temperature dependent (Fig. 25). As seen in Fig. 24, the coefficient $\Delta \mathrm{p} / \Delta \mathrm{T}$ does not show a linear variation with temperature 
described in Eq. (3) because of the variation of the total mean stress and the slight dissipation. This tendency is consistent with earlier results (Braun 2019) which involved undrained thermal laboratory tests.

The fact that the pressurization coefficients measured in situ are higher in the cooling phase is essentially due to the higher temperature during the cooling phase as compared to the heating phase (between 20 and $40{ }^{\circ} \mathrm{C}$ for the heating phase and between 50 and $70^{\circ} \mathrm{C}$ for the cooling phase).

Moreover, for a same temperature it can be explained that $\Lambda *$ is normally higher during the cooling phase than during the heating phase. Indeed, this can be schematically explained by Fig. 26, if we assume that the contribution of the total mean stress is analogous for both heating and cooling phases, it means that the term $\Delta \mathrm{m}$ is similar for heating or cooling material for a given temperature. As specified earlier, a low-permeability porous medium such as claystone reacts to a variation of temperature in a quasi-perfectly undrained condition. However, the in situ conditions are not perfectly undrained meaning that it can have a slight dissipation P1 so the coefficient measured during the heating phase is the following:

$$
\Lambda_{\text {heating }}^{*}=\left(p_{\text {hau }}-p_{0}\right) / \Delta T \text {, }
$$

where $p_{0}$ is the pressure at the considered temperature $T ; p_{\text {hau }}$ and $p_{\text {cau }}$ are, respectively, the heating and cooling pressure in "no perfectly" undrained conditions (the suffix au means almost undrained); $\mathrm{p}_{\mathrm{hu}}$ and $\mathrm{p}_{\mathrm{cu}}$ are the heating and cooling pressure in perfectly undrained conditions. 
Fig. 26

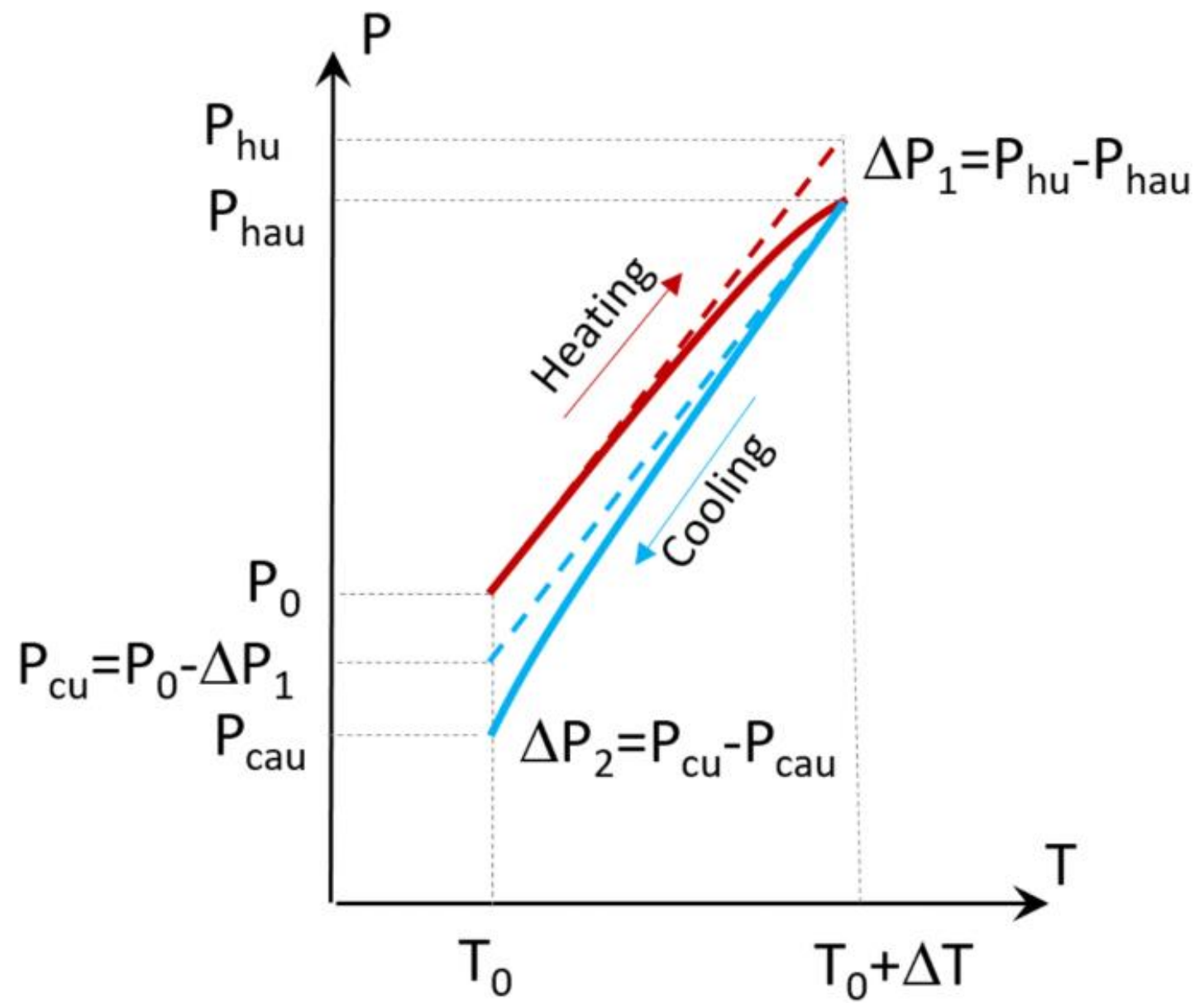

Coefficient $\Delta \mathrm{p} / \Delta \mathrm{T}$ during the heating and cooling phase starting at the same temperature TO

$\Lambda *_{\text {heating }}$ will be lower than the theoretical coefficient described by Eq. (3):

$$
\Lambda=\left(P_{\mathrm{hu}}-P_{0}\right) / \Delta T=\Lambda_{\text {heating }}^{*}+\Delta P_{1} / \Delta T .
$$

Conversely, during the cooling phase, the dissipation leads to a slight decrease in pore pressure $\Delta p 2$ $=p_{c u}-p_{c a u}$ in comparison to theoretical decrease in perfectly undrained condition $p_{c u}-p_{\text {hau. }}$.

Thus, the pressurization coefficient measured in situ during the cooling phase will be as follows:

$$
\Lambda_{\text {cooling }}^{*}=\Lambda+\Delta p_{2} / \Delta T=\Lambda_{\text {heating }}^{*}+\Delta p_{1} / \Delta T+\Delta p_{2} / \Delta T \text {. }
$$

Finally, we observed that the coefficient $\Delta p / \Delta T$ obtained for the same temperature at the TED1252 borehole is higher than those obtained at the TED1250 and TED1251 boreholes for both heating and cooling phases. It is worth noting that borehole TED1252 was located further from the heater than the boreholes TED1250 and TED1251, which were closer to the central heater. Therefore, a change of temperature at the heater (increase or decrease) led to a much smaller change of temperature compared to the change in pore pressure at borehole TED1252 (Fig. 24). Indeed, while the heat transfer response to the heating elements took time because of the thermal characteristics of the claystone, the change in pore pressure was almost instantaneous. This is due to hydro-mechanical 
coupling as discussed above. This phenomenon was less pronounced at the sensors TED1250 and TED1251 because of their proximity to the heater.

\subsubsection{Hydraulic Conductivity Measurements}

The aim of permeability tests was to verify if rock damage will occur during the experiment time. The pressure drops and rises triggered by the pulse-tests can be easily identified on the pressure curves (Figs. 12, 13, 14, 15). After the perturbations provoked by the tests, rapid pressure recovery is observed. The results of the pulse-tests are gathered in Fig. 27. They are presented with respect to time in the different piezometers at $14 \mathrm{~m}$ depth. The dotted lines represent the heat steps. The uncertainty of the measurements can be of 1 order of magnitude.

Fig. 27
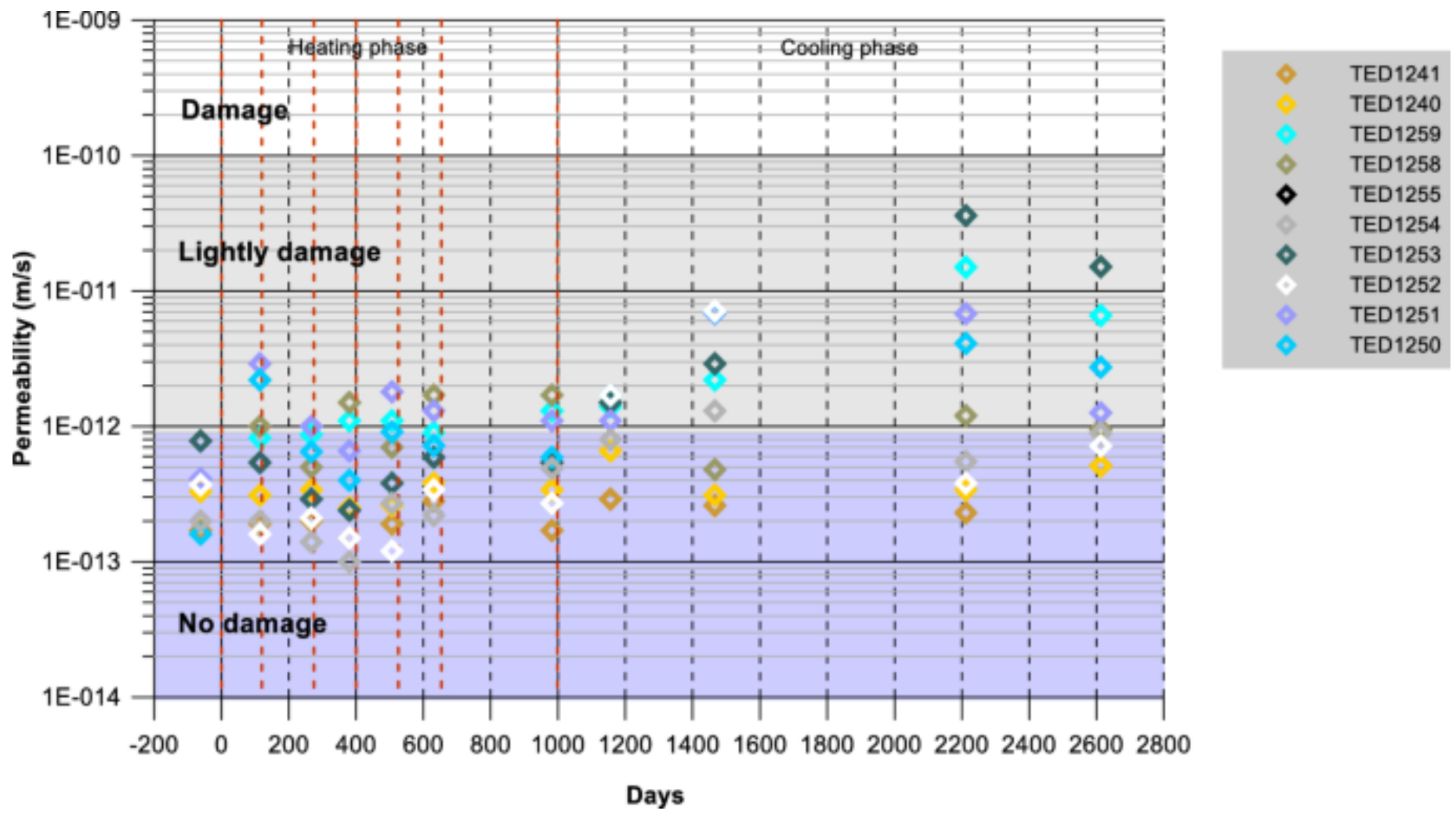

In situ measured hydraulic conductivity at $14 \mathrm{~m}$ depth over time in the different boreholes

In general, it is considered that COx claystone is sound if its hydraulic conductivity is less than $10^{-12}$ $\mathrm{m} \mathrm{s}^{-1}$, lightly damaged for a range of $10^{-10}-10^{-12} \mathrm{~m} \mathrm{~s}^{-1}$ and damaged if the permeability is greater than $10^{-10} \mathrm{~m} \mathrm{~s}^{-1}$. All the estimated values are close to $10^{-12} \mathrm{~m} \mathrm{~s}^{-1}$ and correspond to sound claystone. During the heating phase, these values do not significantly vary over time. Thus, temperature seems not to affect the rock mass and so the permeability field. It can be noticed that because of the uncertainties of the in situ measurement, the influence of increasing temperature on water viscosity and so the increasing of hydraulic conductivity is negligible. This result is consistent with the observation during the other in situ heating experiment (HE-D) and with the laboratory measurements on samples (Zhang et al. 2017).

The initial measurements after heating was stopped (day 1271) do not show any evolution. However, some 200 days after final shutdown (day 1460), the hydraulic conductivity values measured close to the heated area seem to be slightly higher than on day 1271 . Note that all the intervals were at 
atmospheric pressure and partially desaturated. The permeability values were thus probably false because it is affected by these phenomena and are not necessarily representative of the state of the ground. Indeed, the increasing trend seems to have reversed during the two last campaigns (days 2200 and 2600).

\subsubsection{Numerical Modeling}

Numerical simulations are necessary for a full interpretation of such an in situ test. Accurate representation of the initial pressure field is one of the main concerns for providing such calculations. In situ measurements indicate a strong coupling between mechanical and hydraulic processes. Essentially, this means that small deformations imply pore pressure increases or decreases (Armand and Su 2006). An extensive pore pressure survey program has been launched in the M/HM URL to try to ascertain the extent of the hydro-mechanical impact of excavation.

As described in Armand et al. (2015), an overpressure induced in the horizontal direction due to excavation is observed. The amplitude of this overpressure is greater for drifts excavated parallel to the principal horizontal stress ( 1 order of magnitude difference with the vertical plane). A pressure drop is observed near the front face followed by stabilization - as a function of pore pressure gradient. The distance of influence of the excavation is estimated at about $20 \mathrm{~m}$. The mechanisms behind the pore water pressure response around an underground opening are twofold. The first type of mechanism can be associated with nearly undrained behavior, due to the very low permeability of the COx claystone. The short-term changes of the pore pressure field are essentially due to the induced volumetric deformation of the rock mass. In far field, volumetric deformations are related to the elastic behavior and the anisotropic response of the pressure field emphasizes the role of elastic anisotropy (the COx is stiffer in the direction of bedding, i.e. horizontal). In near field, change of stress implies to reach the shear strength of the COX and conduct to fracture opening (Armand et al. 2014) and instantaneous drop of pressure to atmospheric pressure. The second type of mechanism is related to drainage of excess pore water pressure relative to a state governed by the drift wall.

A series of numerical calculations was performed, mainly to calculate the value of some of the THM parameters via back-analysis of the TED experiment (Jobmann et al. 2016; Garitte et al. 2014). Table 1 shows the results of the various back-analyses performed on temperature measurements along with laboratory measurements.

Globally the numerical calculations reproduce well the thermal response of the rock mass using the calibrated thermal conductivity (see Figs. 23, 24, 28). An example of simulation results provided by Jobmann et al. (2016) is presented in Fig. 28. The authors used a statistical method for identification of the COx THM parameters. A Mohr-Coulomb-based elasto-plastic behavior is considered. Shear and tensile failure including softening, when the initial strength values are reached, are considered. The elastic anisotropy is also taken into account. An exponential relation between intrinsic permeability and stress state is introduced for permeability parallel and perpendicular to the bedding plane. An automatic sensitivity analysis and optimization algorithm are used that allow parameter fitting and analysis of the importance of each parameter. 
Fig. 28

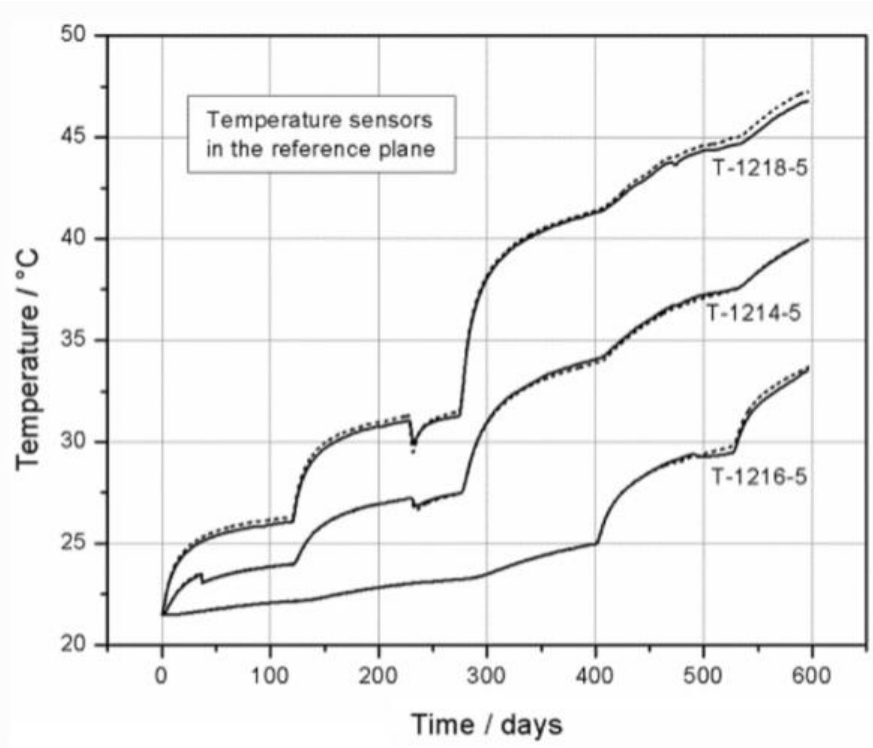

a

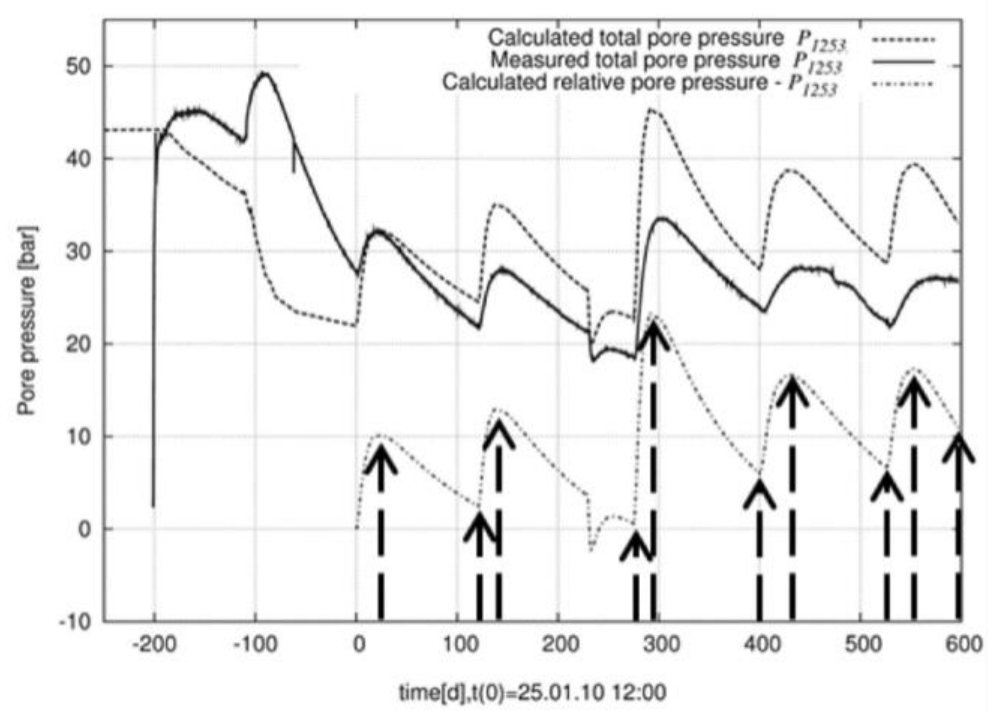

b

History of calculated and measured temperature (a) and pore pressure (b) at different sensors (Jobmann et al. 2016)

As for the pore pressure response, the pore pressure changes are reproduced only qualitatively, essentially due to the difficulty of accurately representing the initial pressure field due to the presence of several boreholes.

\section{Conclusion}

Thanks to detailed heating and cooling history and extensive instrumentation, the TED experiment has provided important information about the COx THM behavior and its response to thermal loading.

In particular, it has highlighted the pore pressure response to a temperature increase in a low permeable claystone. First the pressure increases, due to the difference between the thermal expansion coefficients of pore water and the solid skeleton and thermal stresses. Then, the generated overpressures dissipate, the dissipation rate being governed by the hydraulic conductivity of the host medium. The TED experiment has also shown the anisotropy of the COx THM behavior, affecting both its thermal, mechanical and hydraulic response to a thermal load. TED experiment shows that the permeability field is not affected by the heating indicating that the rock is not damaged at these levels of temperature.

With regard to the evolution of the COx properties, it appears that modeling considering poro-elastic approach with constant thermal and hydro-mechanical properties (i.e. properties not affected by temperature in the range $22-90^{\circ} \mathrm{C}$ ) and changes in the thermal expansion coefficient of water and its viscosity with temperature allow to reproduce the in situ measurements. Using these experimental results, significant THM modeling work was carried out for the TED experiment (Jobmann et al. 2016; Garitte et al. 2014). The purpose of this modeling work was to validate and improve the THM models, and it involved predictive and interpretative calculations. Some models were purely thermal while others included THM interactions. From a thermal standpoint, it appears that the in situ temperature field is perfectly reproduced by modeling and that the values obtained by back-analysis are very close 
to those measured on sample in laboratory test. The reproduction by the THM models of the measured pressure field is also quite good during the heating/cooling phase. Furthermore, poro-elastic modeling provided satisfactory result during the heating test.

The numerical simulation of TED experiment performed in COMSOL Multiphysics software allowed to better understand the pressurization phenomena. It is confirmed that the coefficient $\Delta p / \Delta T$ increased during the heating phase whereas it decreased during the cooling phase due to the thermal expansion coefficient of water being temperature dependent. The value of the coefficient is really linked to the drainage condition in situ. Indeed, in the modeling, the conditions are perfectly drained or not drained which influence the value of the coefficient and explain a part of the difference between the experimental and theoretical values.

With TED experiment, it was showed that comparison between in situ experiment and numerical modeling results have led to a better understanding of THM behavior of COx at different scales and a better characterization of the THM properties.

\author{
Abbreviations \\ $\sigma \mathrm{H}$ : Major horizontal stress \\ $\sigma \mathrm{v}$ : Vertical stress \\ $\sigma \mathrm{h}:$ Minor horizontal \\ $\lambda$ par : Thermal conductivity parallel to the bedding plane \\ $\lambda$ per : Thermal conductivity perpendicular to the bedding plane \\ $\sigma \mathrm{m}$ : Total mean stress \\ $\mathrm{p}$ : Pore pressure \\ $\mathrm{T}:$ Temperature \\ B : Skempton's coefficient \\ $\Lambda$ : Thermal pressurization coefficient \\ $\Lambda *$ : Thermo-mechanical pressurization coefficient \\ $\mathrm{K}$ : Drained bulk modulus \\ Ks : Unjacketed modulus \\ $\mathrm{Kf}$ : Fluid compression modulus \\ of : Volumetric thermal expansion coefficient of pore fluid \\ $\alpha$ : Volumetric thermal expansion coefficient of solid phase \\ $\varepsilon 1$ : Strain along the direction 1 \\ $\varepsilon 2$ : Strain along the direction 2 \\ $\varepsilon 3$ : Strain along the direction 3 \\ $p_{\text {hau }}$ : Heating pore pressure in almost undrained conditions \\ $p_{\text {cau }}$ : Cooling pore pressure in almost undrained conditions \\ $p_{0}:$ Initial pore pressure \\ $p_{\text {hu }}$ : Heating pore pressure in perfectly undrained conditions \\ $\mathrm{p}_{\mathrm{cu}}$ : Cooling pore pressure in perfectly undrained conditions
}




\section{References}

Andra (2005) DOSSIER 2005. Synthesis-evaluation of the feasibility of a geological repository in an argillaceous formation

Armand G, Su K (2006) Hydromechanical coupling phenomena observed during a shaft sinking experiment in a deep argillaceous rock. Geoproc Nanjing 20:725-731

Armand G, Leveau F, Nussbaum C, De La Vaissiere R, Noiret A, Jaeggi D, Landrein P, Righini C (2014) Geometry and properties of the excavation induced fractures at the Meuse/Haute-Marne URL drifts. Rock Mech Rock Eng 20:21-41

Armand G, Noiret A, Morel J, Seyedi D (2015) Pore pressure change during the excavation of deep tunnels in the Callovo Oxfordian claystone. ISRM congress 2015 proceedings-international symposium on rock mechanics

Armand G, Bumbieler F, Conil N, de la Vaissière R, Bosgiraud JM (2017a) Main outcomes from in situ THM experiments programme to demonstrate feasibility of radioactive HL-LLW repository in the Callovo Oxfordian claystone. J Rock Mech Geotech Eng 9:415-427

Armand G, Conil N, Talandier J, Seyedi DM (2017b) Fundamental aspects of the hydromechanical behaviour of Callovo-Oxfordian claystone: from experimental studies to model calibration and validation. Comput Geotech 85:277-286

Bernier F, Neerdael B (1996) Overview of in situ thermo-mechanical experiments in clay: concept, results and interpretation. Eng Geol 41:51-64

Braun P (2019) Thermo-hydro-mechanical behaviour of the Callovo-Oxfordian claystone. Ph.D., Paris Est University

COMSOL Multiphysics ${ }^{\circledR}$ v. 5.3. https://www.comsol.com. Accessed 1 Mar 2019

De Bruyn D, Serge L (2002) The second phase of ATLAS: the continuation of a running THM test in the HADES underground research facility at Mol. Eng Geol 64:309-316

Garitte B, Vaunat J, Gens A, Armand G (2010) 3D Interpretation of an in situ heating test in the CallovoOxfordian mudstone. Clays in natural and engineered barriers for radioactive waste confinement, 29th March-1st April, Nantes, France

Garitte B, Gens A, Vaunat J, Armand G (2014) Thermal conductivity of argillaceous rocks: determination methodology using in situ heating tests. Rock Mech Rock Eng 47:111-129

Ghabezloo S, Sulem J (2009) Stress dependent thermal pressurization of a fluid-saturated rock. Rock Mech Rock Eng 42:1-24

Jobmann M, Li S, Polster M, Breustedt M, Schlegel R, Vymlatil P, Willet J (2016) Using statistical methods for rock parameter identification to analyse the THM behaviour of Callovo-Oxfordian claystone due to heating. J Geol Resour Eng 3:125-136

Mohajerani M, Delage P, Sulem J, Monfared M, Tang AM, Gatmiri B (2012) A laboratory investigation of thermally induced pore pressures in the Callovo-Oxfordian claystone. Int J Rock Mech Min Sci 52:112-121

Monfared M, Sulem J, Delage P, Mohajerani M (2011) A laboratory investigation on thermal properties of the Opalinus claystone. Rock Mech Rock Eng 44:735-747 
Monfared M, Delage P, Sulem J, Mohajerani M, Tang AM (2013) Thermal pressurization in Boom clay. In: Proceedings of the 18th international conference on soil mechanics and geotechnical engineering, Paris, France, pp 3383-3386

Morel J, Bumbieler F, Conil N, Armand G (2013) Feasibility and behavior of a full scale disposal cell in a deep clay layer. EUROCK, Wroclaw

Robinet JC, Sardini P, Coelho D, Parneix JC, Prêt D, Sammartino S, Boller E, Altmann S (2012) Effects of mineral distribution at mesoscopic scale on solute diffusion in a clay-rich rock: example of the CallovoOxfordian mudstone (Bure). Water Resour Res 20:48

Seyedi D, Armand G, Conil N, Vitel M, Vu MN (2017) On the thermo-hydro-mechanical pressurization in Callovo-Oxfordian claystone under thermal loading. Poromechanics VI:754-761

Spang B (2002) Excel add-in for properties of water and steam in si-units

Vu MN, Seyedi D, Armand G (2015) Thermo-poro-mechanical coupled processes during thermal pressurization around Nuclear Waste Repository. 6th coupled problems in science and engineering, May 18-20, Venice, Italy

Vu MN, Armand G, Plua C (2019) Thermal pressurization coefficient of anisotropic elastic porous media. Rock Mech Rock Eng 20:1-5

Wileveau Y, Rothfuchs T (2007) THM behaviour of host rock (HE-D) experiment: study of thermal effects on Opalinus clay. Technical Report 2006-01

Wileveau Y, Su K (2007) In situ thermal experiments carried out in Opalinus claystone and CallovoOxfordian claystones by ANDRA experiment set-up and measurement results. Clay in natural and engineered barriers for radioactive waste confinement. Lille

Wileveau Y, Cornet FH, Desroches J, Blumling P (2007) Complete in situ stress determination in an argillite sedimentary formation. Phys Chem Earth 32:866-878

Zhang CL, Conil N, Armand G (2017) Thermal effects on clay rocks for deep disposal of high-level radioactive waste. J Rock Mech Geotech Eng 9:463-478 